\title{
Tropical Pacific Ocean Response to Observed Winds in a Layered General Circulation Model
}

\author{
ARTHUR J. MiLleR \\ Scripps Institution of Oceanography, La Jolla, California \\ JOSEF M. OBERHUBER \\ Meteorological Institute, University of Hamburg, Hamburg, Germany \\ Nicholas E. Graham and Tim P. Barnett \\ Scripps Institution of Oceanography, La Jolla, California
}

\begin{abstract}
We examine the climatological and anomalous response of an isopycnic coordinate general circulation model, with embedded bulk surface mixed layer model, when forced by observed monthly mean wind stress variability. Our results show that model fields of sea surface temperature (SST) and currents are fairly similar to those arising in other models as well as published observations. The model generates a climatology of SST which is usually within $0.5^{\circ}-1.5^{\circ} \mathrm{C}$ of the Comprehensive OceanAtmosphere Data Set observations. Anomalous SST compares best with observations when averaged over rather large spatial regions. The mean horizontal currents tend to resemble the observed, but the amplitudes are smaller than observed (primarily because the model predicts vertical mean currents in the mixed layer rather than the surface currents) and the springtime reversal of the South Equatorial Current is absent in the model. Anomalous zonal currents are similarly reduced in amplitude though the variability is comparable to the available observations. We also describe the model's basin-scale mean mixed-layer structure and the mean vertical velocity field (which is fundamentally different from that of the Geophysical Fluid Dynamics Laboratory model). We discuss various aspects of the 1982-1983 El Niño in particular detail, including the heat budget of the variable-depth tropical Pacific surface mixed layer, and the relationships among anomalies of mixed-layer depth, thermocline depth, and SST. By these analyses, we identify the strengths and weaknesses of the model's capability to simulate observations, particularly with respect to that of other models. Throughout the paper, we attempt to identify the primary areas which require improvement in the model and suggest possible remedies.
\end{abstract}

\section{INTRODUCTION}

The tropical Pacific Ocean appears to significantly affect short-term climate variations both locally and remotely. Compiling a better understanding of climatological and anomalous equatorial conditions is an important goal of oceanography. Since oceanic observations are so difficult to obtain over long time intervals and large spatial scales, there is great interest in using numerical models to help fill the gap between theories and observations.

Many numerical models of the tropical Pacific have been discussed in the literature (see Philander [1990] for a detailed overview), most of which are based on discretization in the vertical. In this paper we discuss a relatively new, layered general circulation model which we have applied to the tropical Pacific. This model is constructed with isopycnal interior layers which are fully coupled to a surface bulk mixed layer having arbitrary density.

The primary interest in using isopycnal models is that mixing in the interior ocean is usually considered to occur predominantly along isopycnals. This model can therefore

Copyright by the American Geophysical Union.

Paper number 92JC00273. 0148-0227/92/92JC-00273\$05.00 be viewed as being built in a more natural geometry than vertical grid point models, because the layer coordinate correspond to surfaces of strongest lateral mixing. Crossisopycnal mixing processes can then be more precisely controlled in the layer model. At the air-sea interface, in contrast, strong vertical mixing occurs which results in surface mixed layers. In this layer model, the turbulent surface mixed layer is modeled after the bulk Kraus and Turner [1967] formulation and is fully coupled to the underlying isopycnal layers.

It is compelling to study how this type of model compares with the classic $z$ coordinate models of ocean circulation and we will therefore compare the response of the OPYC layer model of Oberhuber [1990] with that of various published models, which we briefly summarize as follows. The Geophysical Fluid Dynamics Laboratory (GFDL) model of the Pacific, discussed by Philander and Siegel [1985] (hereinafter PS85) and Philander et al. [1987] (hereinafter PHS87), is often considered the benchmark model of tropical ocean circulation processes. It invokes the Richardson-numberdependent vertical mixing parameterization of Pacanowski and Philander [1981] and includes relatively high resolution, resolving even 20-day waves which occur in the tropical Pacific. The model of Latif [1987] (hereinafter L87) is similar in many respects to the GFDL model but has coarser 
resolution, differing parameter choices, and different atmospheric forcing. The model of Seager [1989] (hereinafter S89) is a shallow-water, single-layer model, which predicts the currents and thermocline temperature that influence a constant-depth sea surface temperature (SST) model. A novel feature of the S89 model is its formulation for the determination of heat fluxes without reference to air temperature and humidity.

This discussion is concerned with several features of the model response, including the mean seasonal cycle response to climatological atmospheric forcing and the anomalous response to observed atmospheric winds from 1970 to 1985. The benchmarks for comparison are the published results from similar experiments using the aforementioned models as well as the available published data. Our main sources of verifying observations are taken from the Comprehensive Ocean-Atmosphere Data Set (COADS) [Woodruff et al., 1987] for monthly-mean, climatological and anomalous sea surface temperature (SST), the mid-Pacific meridional transects of Wyrtki and Kilonsky [1984] for annual-mean, sub-surface thermal and velocity structure, and the current meter records of Halpern [1987] for a long-term point measurement of velocity and temperature.

We first describe the model specifics in section 2 , and present a summary of the climatological response for SST, mixed-layer depth, and horizontal and vertical velocity in section 3. We then examine the anomalous variability of several variables in a simulation of the period 1970-1985 in section 4 , followed by a detailed description of the anomalous response for the 1982-1983 El Niño in section 5. Our results show that the model fields of SST, sea level, and currents are fairly comparable to those shown in published observations and in published discussions of other models, although deficiencies still exist in this version of OPYC. In section 6 , we identify aspects of the model where improvement should be made and describe preliminary experiments being conducted to that end.

\section{Model Dynamics}

The isopycnic model with embedded mixed layer (designated as OPYC) which is used in this study is a preliminary version of the model developed by Oberhuber [1986, 1990]. The interior of the ocean comprises eight isopycnal layers. The bulk surface mixed layer model is a descendant of the formulation of Kraus and Turner [1967]. The model is coded in a very versatile fashion allowing arbitrary geometry, topography, and discretization to be specified for flow on a sphere. Extensive discussions of the numerical schemes and details of the model formulation are given by Oberhuber [1986, 1990]. Note that in this version of the model, upstream horizontal differencing is used, since the Bleck and Boudra [1981] potential vorticity and energy conserving scheme, applied by Oberhuber [1990], had not yet been implemented at the start of this study. For completeness, the equations of motion for the model are now briefly discussed.

\subsection{Interior Isopycnic Layers}

The primitive equations of motion are formulated in flux form as conservation equations for the vertical means of the mass flux, $\Psi_{k}=(\rho \mathbf{v} h)_{k}$, the mass content $\Phi_{k}=(\rho h)_{k}$, the heat content $\Theta_{k}=(\theta \rho h)_{k}$ and the salt content $\Pi_{k}=(S \rho h)_{k}$, in the $k$ th layer:

$$
\begin{aligned}
\frac{\partial}{\partial t} \Psi_{k}= & -\nabla\left(\mathbf{v}_{k} \Psi_{k}\right)-h_{k} \nabla p_{k}-\mathbf{f} * \times \Psi_{k}+\nabla \cdot A_{k}^{m} \nabla \Psi_{k} \\
& +(w \rho \mathbf{v})_{k}^{k+}+(w \rho \mathbf{b} f v)_{k}^{k-}-(w \rho \mathbf{v})_{k+}^{k} \\
& -(w \rho \mathbf{v})_{k-}^{k}+\tau_{k}^{k-}+\tau_{k}^{k+}
\end{aligned}
$$$$
\frac{\partial}{\partial t} \Phi_{k}=-\nabla \cdot \Psi_{k}+(w \rho)_{k}^{k+}+(w \rho)_{k}^{k-}-(w \rho)_{k+}^{k}
$$$$
-(w \rho)_{k-}^{k}+R_{k}^{(P-E)}
$$

$$
\begin{array}{r}
\frac{\partial}{\partial t} \Theta_{k}=-\nabla \cdot(\Theta \mathbf{v})_{k}+\nabla \cdot A_{k}^{s} \nabla(\Theta)_{k}+\frac{Q_{k}}{c_{p}}+(w \rho \theta)_{k}^{k-} \\
+(w \rho \theta)_{k}^{k+}-(w \rho \theta)_{k-}^{k}-(w \rho \theta)_{k+}^{k}
\end{array}
$$

$$
\begin{aligned}
\frac{\partial}{\partial t} \Pi_{k}=-\nabla \cdot(\Pi \mathbf{v})_{k} & +\nabla \cdot A_{k}^{s} \nabla(\Pi)_{k}+(w \rho S)_{k}^{k-} \\
& +(w \rho S)_{k}^{k+}-(w \rho S)_{k-}^{k}-(w \rho S)_{k+}^{k}
\end{aligned}
$$

where $\rho$ is the density, $\mathrm{v}$ is the horizontal velocity vector, $h$ is the layer thickness, $\theta$ is the potential temperature, $S$ is the salinity, $p$ is the pressure, $A^{m}$ and $A^{s}$ are the eddy momentum and scalar (temperature/salinity) diffusion fields, $c_{p}$ is the specific heat of seawater, $Q$ is the heat flux, $R_{k}^{P-E}$ is the freshwater flux due to precipitation minus evaporation (zero except for layer $k=1$ ), and $\tau$ is the stress. The terms which include $w$ represent exchange processes between layers through entrainment/detrainment, cross-isopycnal mixing, and convection. The terminology ( $)_{k}^{l}$ indicates a transfer from the $l$ th layer to the $k$ th layer.

The stress between neighboring layers is parameterized as

$$
\boldsymbol{\tau}_{k}^{\prime}=c_{d} \rho_{a} \sqrt{\Delta \mathbf{v}^{2}} \Delta \mathbf{v} \quad \Delta \mathbf{v}=(\Delta u, \Delta v)=\left(u_{l}-u_{k}, v_{l}-v_{k}\right)
$$

For the internal stresses, the drag coefficient $c_{d}=10^{-4}$, and for the bottom stress, $c_{d}=10^{-3}$. The wind stress, heat flux and freshwater flux are discussed in section 2.3.

The density is related to temperature, pressure, and salinity by the equation of state for seawater [UNESCO, 1981]. The operators in spherical coordinates $(\lambda, \phi)$, with the radius of the Earth, $r$, are

$$
\begin{gathered}
\nabla \cdot=\left(\frac{\partial}{r \cos \phi \partial \lambda}, \frac{\partial}{r \cos \phi \partial \phi} \cos \phi\right) . \\
\nabla=\left(\frac{\partial}{r \cos \phi \partial \lambda}, \frac{\partial}{r \partial \phi}\right)
\end{gathered}
$$

while the parameter $f^{*}$ is related to the Earth's rotation by

$$
f_{k}^{*}=2 \Omega \sin \phi+u_{k} \frac{\tan \phi}{r}
$$

where $\Omega$ is the angular velocity of the Earth. The diffusion coefficients are parameterized [Smagorinsky, 1963] as

$$
A^{s}=c \sqrt{\left(\frac{\partial u}{\partial x}-\frac{\partial v}{\partial y}\right)^{2}+\left(\frac{\partial u}{\partial y}+\frac{\partial v}{\partial x}\right)^{2}}+A_{0}^{s}
$$




$$
\begin{aligned}
& A_{x}^{m}=\frac{\Delta x^{2}}{A_{0} \cos \phi}+A^{s} \\
& A_{y}^{m}=\frac{\Delta y^{2}}{A_{0} \cos \phi}+A^{s}
\end{aligned}
$$

where $A^{m}=\left(A_{x}^{m}, A_{y}^{m}\right)$, with $c=10^{9} \mathrm{~m}^{2}$, the minimum scalar diffusion coefficient $A_{0}^{s}=2000 \mathrm{~m}^{2} \mathrm{~s}^{-1}$, and $A_{0}=2$ $\times 10^{6} \mathrm{~s}$.

\subsection{Surface Mixed-Layer Model}

The surface boundary conditions for the interior flow are determined via the bulk mixed-layer model which is forced by the atmosphere. The mixed layer has the same dynamics as the isopycnal layers except that the temperature and salinity are arbitrary. The equation for the entrainment rate $w$ in the mixed layer is

$$
\begin{gathered}
w g^{\prime} h-w R i_{\text {crit }}\left(\Delta u^{2}+\Delta v^{2}\right)=2 m_{0} a u_{*}^{3}+h b\left(B-\gamma B_{s}\right) \\
+\gamma b B_{s}\left[h\left(1+e^{-h /^{h} B}\right)-2 h_{B}\left(1-e^{-h /^{h} B}\right)\right]
\end{gathered}
$$

where

$$
\begin{gathered}
g^{\prime}=g \frac{\sigma_{\theta 1}-\sigma_{\theta 1}+}{\sigma_{\theta 1}} \\
B=\frac{g}{c_{p} \rho^{2}}(\alpha Q+\beta R) \\
R=\frac{c_{p} \rho}{S}(P-E) \\
B_{s}=\frac{\alpha g}{c_{p} \rho^{2}} Q_{s} \\
b=\exp \left(-\frac{h f}{\kappa u_{*}}\right) \quad B<0 \\
b=\exp \left(-\frac{h f}{\mu u_{*}}\right) \quad B>0
\end{gathered}
$$

where $R i_{\text {crit }}$ is the critical Richardson number $(=0.25), m_{0}$ $=1.5, \gamma=0.42, h_{B}=20 \mathrm{~m}, u_{*}$ is the friction velocity, $\sigma_{\theta}$ is the potential density, $Q_{s}$ is the solar radiative heat fux, $f$ $=2 \Omega \sin \phi$, and $\alpha$ and $\beta$ are the analytically determined expansion coefficients. The minimum mixed layer depth is 5 m. As was suggested by Oberhuber [1990], the turbulent kinetic energy (TKE) dissipation is assumed to be dependent on the Ekman layer length scale, i.e.,

$$
a=\exp \left(-\frac{h f}{\kappa u_{*}}\right)
$$

to keep mid-latitude mixed layers from becoming too deep (in consequence of the geographically fixed mixed-layer parameters), with $\kappa=0.4$ and $\mu=2$ being determined by optimization experiments. Following Oberhuber [1990, 1988], the TKE input is taken from COADS observations prepared by Wright [1988] of the mean wind $\bar{V}$ and its standard deviation $\sigma(V)$. Since monthly mean $u_{*}{ }^{3}$ will be severely underestimated from monthly mean winds, the effective monthly mean $u_{*}{ }^{3}$ is approximated by

$$
u_{*}^{3}=\left(\frac{c_{d} \rho_{a}}{\rho}\right)^{3 / 2} \bar{V}\left[\bar{V}^{2}+3 \sigma^{2}(V)\right]
$$

The coupling of the mixed layer to the interior, discussed by Oberhuber [1990], conserves momentum, mass, heat, and salt.

\subsection{Model Geometry and Timing}

We integrate the model for the region of the Pacific extending from $40^{\circ} \mathrm{S}$ to $65^{\circ} \mathrm{N}$ latitude and $120^{\circ} \mathrm{E}$ to $70^{\circ} \mathrm{W}$ longitude in spherical geometry on a 75 by 58 grid, with otherwise realistic basin shape and topography. The latitudinal resolution is enhanced at the equator (maximally $0.5^{\circ}$ ) and gradually decreases to $4.0^{\circ}$ resolution in the midlatitudes. The longitudinal resolution is enhanced near the eastern and western boundaries to a maximal resolution of $1.4^{\circ}$ (to better resolve wave reflections) and gradually decreases to $4.0^{\circ}$ in the interior. A semi-implicit time-stepping procedure is used allowing a time step of 1 day. The computational cost on the Lawrence Livermore National Laboratory (LLNL) Cray-2 ( $f$ machine) for this nine-layer version is $36 \mathrm{~s}$ per step (on a single processor), or about 3.6 CPU hours per model year. Running on a single processor on the Cray Y-MP at the San Diego Supercomputer Center (SDSC) requires about $18 \mathrm{~s}$ per step, or about $1.8 \mathrm{CPU}$ hours per model year.

\subsection{Atmospheric Forcing and Model Cases}

In all of the experiments, atmospheric fields of air temperature, humidity, cloudiness and TKE input are climatological monthly-mean fields from the COADS [Woodruff et al., 1987; Wright, 1988; Oberhuber, 1988]. Instead of specifying the surface freshwater flux $R_{\mid}^{(P-E)}$ from observations, the surface salinity field is Newtonianly relaxed to the Levitus [1982] annual mean field with a relaxation constant of $5 \times$ $10^{-6} \mathrm{~m} \mathrm{~s}^{-1}$, while the salinity in the interior (isopycnal) layers is dynamically determined with no such constraint. Since all the atmospheric fields are monthly means, they are linearly interpolated to daily values for model forcing by assuming the monthly mean value applies to the fifteenth of the month.

The surface heat flux, $Q_{1}$, consists of short-wave, longwave, sensible and latent heat fluxes. (We hereinafter refer to model cases which compute and use all four heat fluxes as including "complete heat fluxes.") The sensible and latent heat fluxes are computed according to the bulk formulae,

$$
\begin{gathered}
Q_{H}=\rho_{a} \hat{c}_{p} c_{H} V\left(T_{a}-T_{s}\right) \\
Q_{L}=\rho_{a} L_{w} c_{L} V\left(q_{a}-q_{s}\right)
\end{gathered}
$$

where $T_{a}$ is the air temperature, $T_{s}$ is the ocean (model) surface temperature, $q_{a}$ is the specific humidity, $q_{s}$ is the saturation humidity, $\hat{c}_{p}$ is the specific heat of air, $L_{w}$ is the latent heat of evaporation, and $c_{H}$ and $c_{L}$ are the stability dependent sensible and latent heat transfer coefficients. The insolation (a function of season, latitude, and latitudinally specified cloud cover) and long-wave radiation (a function of $T_{a}, T_{s}$, and latitudinally specified cloud cover) is calculated 
in the manner described by Oberhuber [1990]. The interior heat fluxes, $Q_{k}$, can be nonzero owing to insolation.

The wind stresses used in this study are the Hellerman and Rosenstein [1983] (hereinafter H-R) observations and the stresses derived from the (detrended) Florida State University observations from 1961 to 1987 [Goldenberg and O'Brien, 1981] (hereinafter FSU). These wind fields were used instead of COADS winds because they were already available to us at the commencement of this study and because we desired to compare our results with other models forced by FSU stresses. A constant drag coefficient of 0.0015 , which is a typical value employed by other investigators, is used to convert the FSU psuedostress into stress. For the climatological spin-up phase of the simulation, the monthly means of FSU psuedostress for the interval 19611987 were computed and used as forcing. Since the FSU winds only apply to $\pm 30^{\circ}$ of latitude, the H-R winds are used for higher latitudes in runs that include FSU winds.

We now discuss the detailed scenarios of the four cases, all of which are in seasonal cycle mode: case A, spin-up experiments ( $>25$ years) with H-R mean wind stress (complete heat fluxes); case B, spin-up experiments (11 years) with FSU monthly mean wind stress (complete heat fluxes); case C, FSU observed winds for 1961-1973 (complete heat fluxes); and case D, FSU observed winds for 1970-1985 (quasi-Newtonian heat flux damping). In case $A$ the model was initially spun up using H-R wind stress and included complete heat fluxes; this run also formed the basis for some parameter testing. Next, in case B, 11 model years were integrated using forcing derived from mean FSU winds and heat, again with complete heat fluxes; further parameter testing was carried out during this run. As a preliminary experiment using observed winds, case C used the 19611973 FSU monthly mean observed winds as forcing, with initial conditions from the seasonal mean run and complete heat fluxes. Finally, case D, which is described in the greatest detail in section 3, 4, was forced with FSU winds from 1970-1985 with initial conditions from the 1961-1973 run. The heat fluxes for this run were computed in a quasi-Newtonian fashion as described below.

In cases $C$ and $D$, note that although the wind stresses are the only atmospheric variable which is allowed to vary according to their observed monthly mean values, the corresponding wind speed variation affects the computation of heat flux in (11) and (12). We again emphasize that the TKE input into the mixed layer in all four cases is always the climatological monthly mean. This is because of the extreme uncertainty in estimating the mean $u_{*}^{3}$ for a given month from only the monthly mean wind.

As will be discussed later, the use of climatological monthly mean atmosphere fields for computing heat fluxes in case $C$ resulted in weak SST anomalies in part because the resulting heat flux anomalies drive the model too strongly back toward climatology [Schopf, 1983]. To reduce the amplitude of the surface heat flux anomalies in case $D$, we used a modified Newtonian damping scheme for the heat fiuxes. From the output of case $\mathrm{C}$, a model climatology of SST, $\bar{T}_{s}(x, y, t)$, and of total surface heat flux, $\bar{Q}(x, y, t)$, was computed for each day (i.e., 13 values (one per year) contribute to the mean for a given day). For case $D$ we invoked an atmospheric feedback relation as follows:

$$
Q(x, y, t)=\bar{Q}+\varepsilon \frac{d \tilde{Q}}{d T_{s}}\left(T_{s}-\bar{T}_{s}\right) A+\widetilde{Q}(1-A)
$$

where $\bar{Q}$ is the complete surface heat flux computed normally, as in cases $A-C$, and

$$
A(\phi)=e^{-(\phi / L)^{2}}
$$

with $e$-folding scale $L=18^{\circ}$ latitude, is the latitudinal function of influence for the parameterization. This latitudinal factor keeps the SST anomalies in the middle latitudes from becoming too large and persistent. Clearly, if $\varepsilon=1$, the heat flux parameterization represents an expansion of the complete heat flux anomaly about the climatological SST, evaluated linearly for the present SST anomaly. If $\varepsilon=0$, the perturbation heat fluxes are completely shut off in the equatorial zone. On the basis of several test runs for the year 1972 , we selected $\varepsilon=\frac{1}{3}$ which resulted in SST anomalies of reasonable size for that year.

The parameterization (13) yields a space- and timedependent Newtonian relaxation time scale based on the model's heat flux sensitivity to SST $\left(d Q / d T_{s}\right)$. We emphasize that the SST in the $1970-1985$ run (case D) relaxes to the model mean SST of the 1961-1973 run (case C), not to the observed mean SST, and that the perturbation surface heat flux is with respect to the model mean heat flux, $\bar{Q}$, from case $\mathrm{C}$.

\section{Climatological Response}

\subsection{Comparison of the Four Cases}

The biggest difference in climatological model response occurred when changing from the H-R winds (case A) to the FSU mean winds (case B), since the pattern of the FSU wind stress was somewhat different than the H-R wind stress. The strength of the North Equatorial Countercurrent (NECC) and North Equatorial Current (NEC), the strength of the meridional velocity field, and the seasonal appearance/ disappearance of the NECC, seemed to be more realistic (and more comparable to the results of PHS87, which were obtained with H-R winds) when OPYC was forced with H-R wind stress. Differences in the wind stress curl, which is sensitive to poor data coverage, and the amplitude of the stresses are the main reasons for these results.

Not surprisingly, the differences between the long-term mean model response in case B (annual cycle of FSU wind stress) and that in cases C and D (observed FSU wind stress) were minor. For example, the mean SST field near the date line exhibited a stronger cold bias in the mean response to variable winds (cases $C$ and $D$ ) than for the mean response to mean winds (case $B$ ). This is the region where observed wind variability is large and the mean winds are weak and thus is the place in the model where one could expect some rectification of response. Because the mean SST field arising from variable winds in the 1961-1973 case typically differed by less than $1^{\circ} \mathrm{C}$ from the SST response in the mean FSU winds case, we did not carry out a detailed study of the rectification of response in any of the model fields.

As expected, the model climatology for case D differed little from case $C$ (the SST in case D was relaxed to the monthly mean SST from case C). A small difference in SST climatology does, of course, occur due to differing rectification effects and/or to the presence of a different ratio of El Niño events to La Niña events. 


\section{2. $S S T$}

The mean SST field is probably the most important response to be represented by the model because anomalous currents acting on the mean SST gradients create the greater part of anomalous SST variability. Some models avoid the complication of establishing an acceptable SST climatology by designing anomaly models or by relaxing the SST to the observed field. For the formulation used here, there is also concern [e.g., Seager et al., 1988] that since the observed climatological air temperature is used in the heat-flux bulk formulae, and because SST is observed to follow air temperature rather closely, that we are building the observed SST field into the model. This is not necessarily true, since we have found that changes in model parameters, especially mixed-layer parameters, can result in changes of several degrees in the mean SST fields near the equator. The prime reason for this is that we compute total heat flux which includes radiation, latent heat and sensible heat, the formulae for which depend upon insolation, humidity, wind speed, etc.; the contribution of sensible heat is small compared to latent heat and radiation.

Figure 1 shows the mean SST error field (simulation less observed) for April and October for case C. A dominant feature during most of the year is a cold bias of between $0.5^{\circ}$ and $1.5^{\circ} \mathrm{K}$ along most of the equator, due to zonal advection effects being too strong in the surface mixed layer, resulting in excessive cooling by horizontal advection. This is partly the result of choosing a sufficiently small coefficient for the horizontal diffusion of momentum, which allows a relatively strong undercurrent but has the added effect of allowing mixed-layer currents which are too strong in the west central equatorial Pacific. These westward surface currents are decelerated in nature by surface eddies for which there is no analogous mechanism in this model. (We subsequently found that the potential vorticity and energy conserving horizontal discretization scheme of Bleck and Boudra [1981], owing to its superior treatment of momentum divergence and the resulting diminishing of western Pacific surface currents, results in a more realistic cold tongue.) In the spring months off the coast of South America, between $5^{\circ} \mathrm{S}$ and $20^{\circ} \mathrm{S}$, mean SST is excessively warm, with the error exceeding $2^{\circ} \mathrm{C}$ in some places. Along the equator, the rms error (not shown) for the 12 monthly means is about $0.3^{\circ} \mathrm{C}$ in the western Pacific, peaks near $160^{\circ} \mathrm{W}$ at a value of about $1.1^{\circ} \mathrm{C}$, and is about $0.6^{\circ} \mathrm{C}$ in the eastern Pacific.

\subsection{Mixed-Layer Depth}

Of particular interest is the model surface mixed-layer depth (MLD) because of its important influence in SST variability. As is shown in Figure 2 for case D, along the equator the mean MLD is shallow $(5-20 \mathrm{~m})$ in the east and thickens $(80-100 \mathrm{~m})$ in the central Pacific, as is observed in the upper ocean temperature structure. In the western Pacific, however, the mixed layer shoals to depths of the order of $40 \mathrm{~m}$, in contrast to the much larger depth of the model $20^{\circ}$ isotherm (Figure 3), an indicator of the thermocline. The discrepancy between the shallow MLD and the depth of the thermocline is explained by the low TKE input in the western Pacific; the MLD there is controlled by the size of the available TKE rather than the temperature profile. The nearly isothermal surface layer is only a threshold for the maximal MLD which can appear in conjunction with that temperature profile. Note also that the model's representation of the thermocline (Figure 3 ) is much more diffuse than observations (which is similar to results from other models) and that the isotherms below the thermocline in the eastern Pacific fail to slope downward and eastward in contrast to observations and the models of PHS91 and Gordon and Corry [1991].

In the central Pacific the poleward transport of cooler water (from equatorial upwelling driven by Ekman currents) weakens the upper ocean stratification and thereby results in deep mixed layers (150-200 m) just north and south of the equator (Figure 2). Similar thermal mixing occurs off the equator in the simulation of PHS87 (their Figure 6), though not to so great a depth. Although a weak upper ocean stratification poleward of the equator is evident, for example, in the observations of Wyrtki and Kilonsky [1984], the present model appears to overestimate the depth of the mixed layer there. The resulting horizontal density gradients just poleward of the equator serve to maintain the strength of the zonal surface currents at the equator.

It is difficult to verify the model MLD structure, since there are few observations of the turbulent surface MLD in the tropical Pacific (for example, expendable bathythermograph (XBT) measurements can show thermocline depth but not the turbulent MLD) and other models do not include a turbulent bulk mixed layer. (Schopf and Cane [1983] discussed a model which included a mixed layer but they did not force it with observed seasonally varying winds.) Exacerbating the problem is that the MLD in the western Pacific responds sensitively to both TKE input and buoyancy fluxes. Since there are few observations of the highly variable winds near the date line, the estimate of the mean TKE input probably contains large errors, so that the model MLD field should be interpreted with caution.

\subsection{Horizontal Velocity}

The surface current field of this model exhibits the basic features of the observed circulation. The fall appearance and spring demise of the North Equatorial Countercurrent are evident in the surface current fields shown in Figure 4 for case D. The structure of the NECC during these months is comparable to that simulated by PHS87 with the GFDL model in seasonal cycle mode. However, although the South Equatorial Current (SEC) does weaken in the spring (e.g., Figure $8 a$ ), its springtime reversal which is observed in the eastern Pacific [Halpern, 1987; McPhaden and Hayes, 1990] due to the weakened trade winds is not captured by this model; the GFDL model, in contrast, does simulate this reversal, albeit with a weaker amplitude than observed [PHS897; Chao et al., 1991 ; D. E. Harrison, On the seasonal cycle of equatorial zonal currents at $110^{\circ} \mathrm{W}$ and $140^{\circ} \mathrm{W}$ : Some circulation model results and dynamics, submitted to Journal of Geophysical Research, 1992, hereinafter Harrison, submitted].

Another problem with this model's horizontal current field is its low amplitude with respect to observations and other tropical models. In particular, the surface current field and the Equatorial Undercurrent are typically $50-80 \%$ of the speed of those observed. This is primarily due to the surface current field representing the average over the bulk mixed layer (which may have a baroclinic velocity response in reality) rather than currents at, say, the 5-m level of a $z$ coordinate model or those observed at the surface of the ocean. Another reason for the discrepancy with PHS87 is the differing wind stress fields; the NECC is sensitive to the curl 


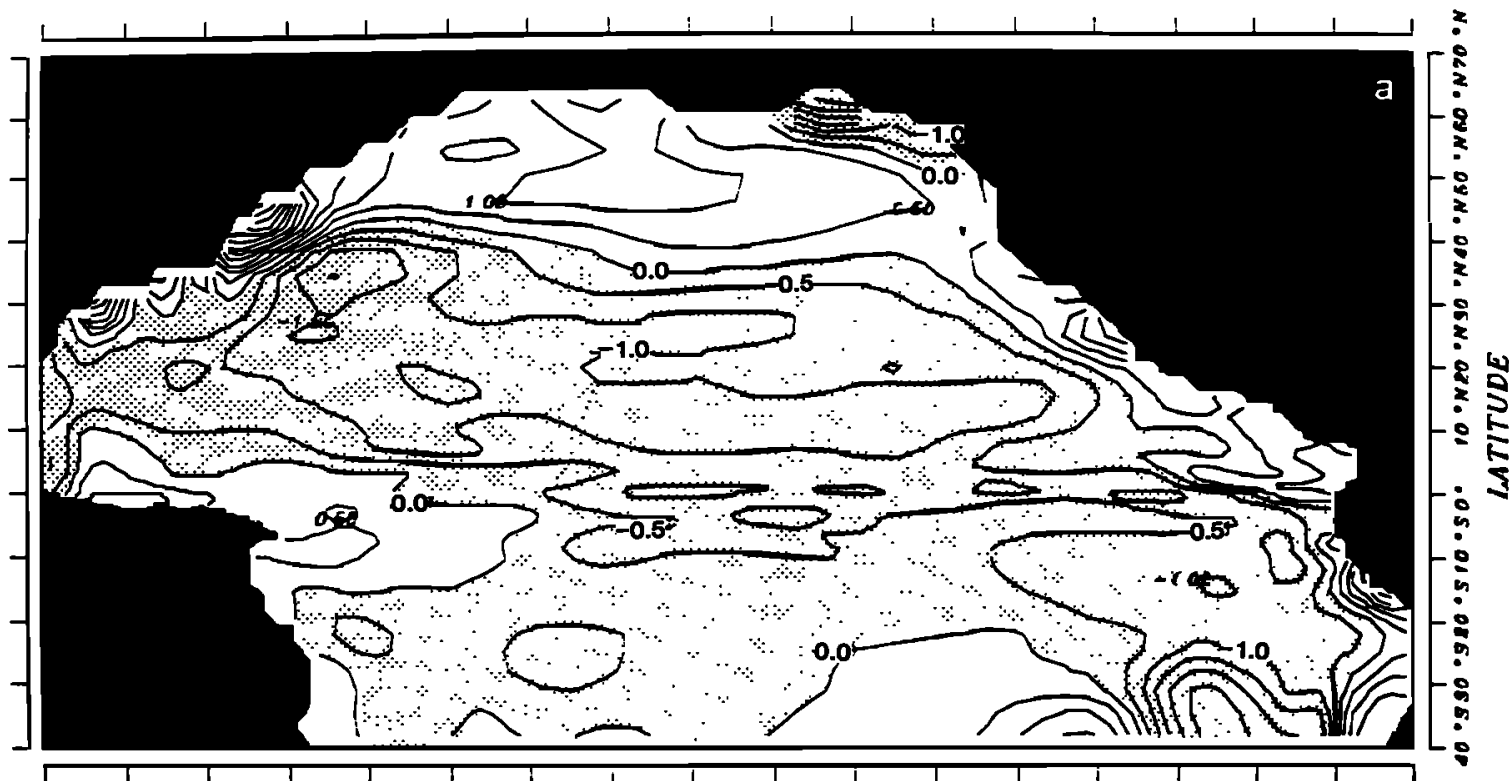

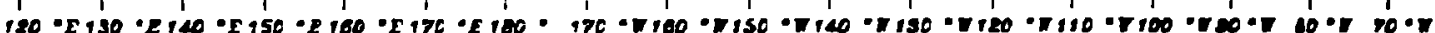
LONGITUDE

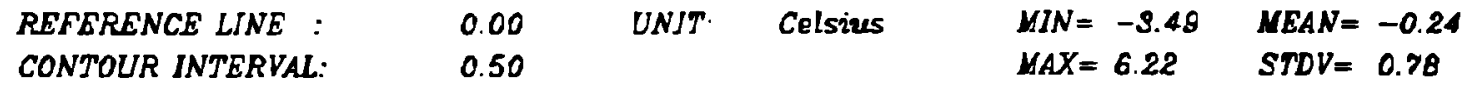

\section{SEA SURFACE TEMPERATURE OCtober Mean ETror}

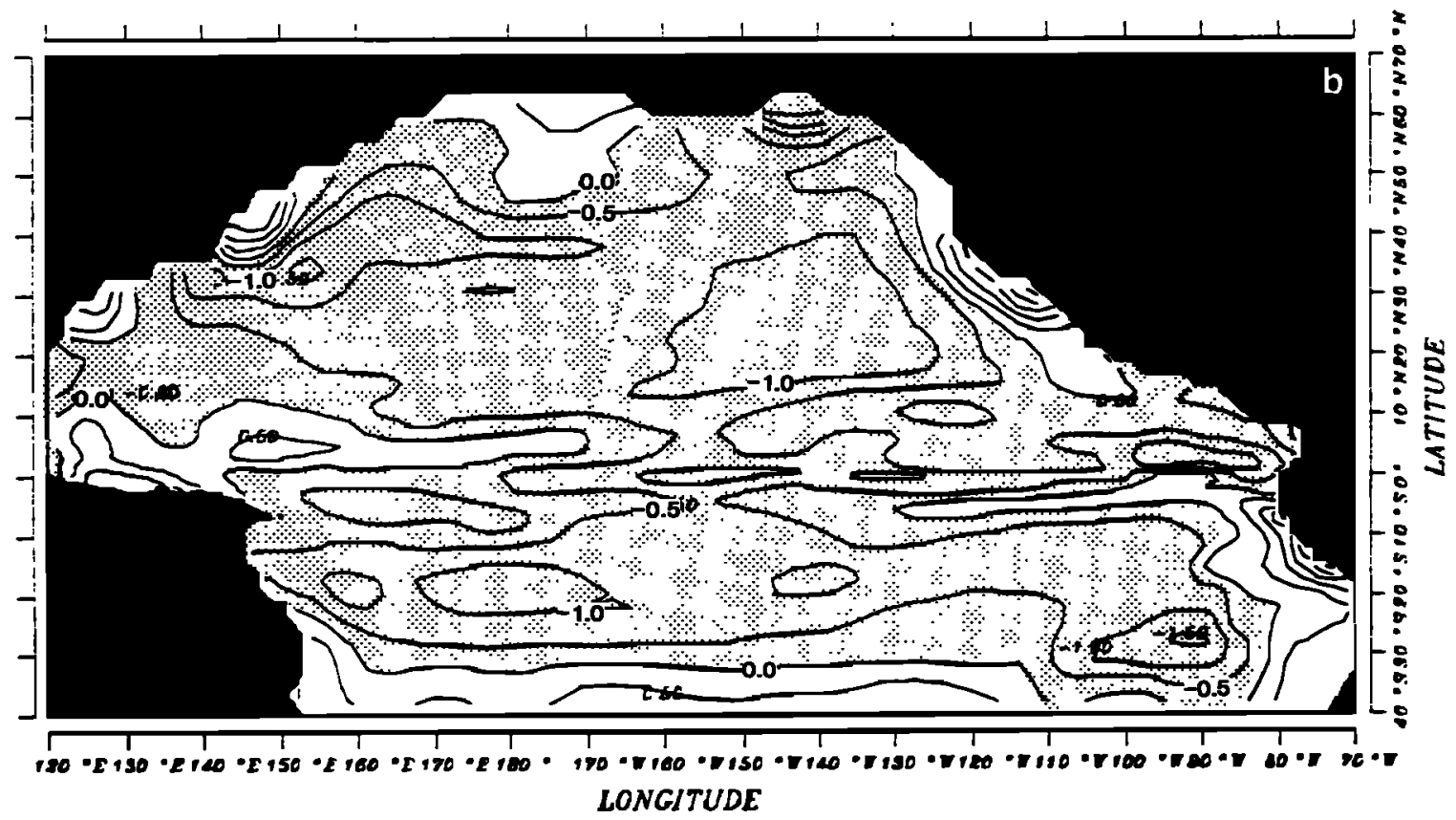

$\begin{array}{llllll}\text { REFERENCE LJNE : } & 0.00 & \text { UNIT } & \text { Celsizs } & \text { MIN }=-2.97 & \text { MEAN }=-0.26 \\ \text { CONTOUR INTERVAL: } & 050 & & & \text { MAX }=2.99 & S T D V=0.58\end{array}$

Fig. 1. Mean SST error for the model for $(a)$ April and $(b)$ October, computed as the difference between the 13-year mean of the 1961-1973 simulation (case C) and the COADS observations. Stippled regions indicate negative error. 

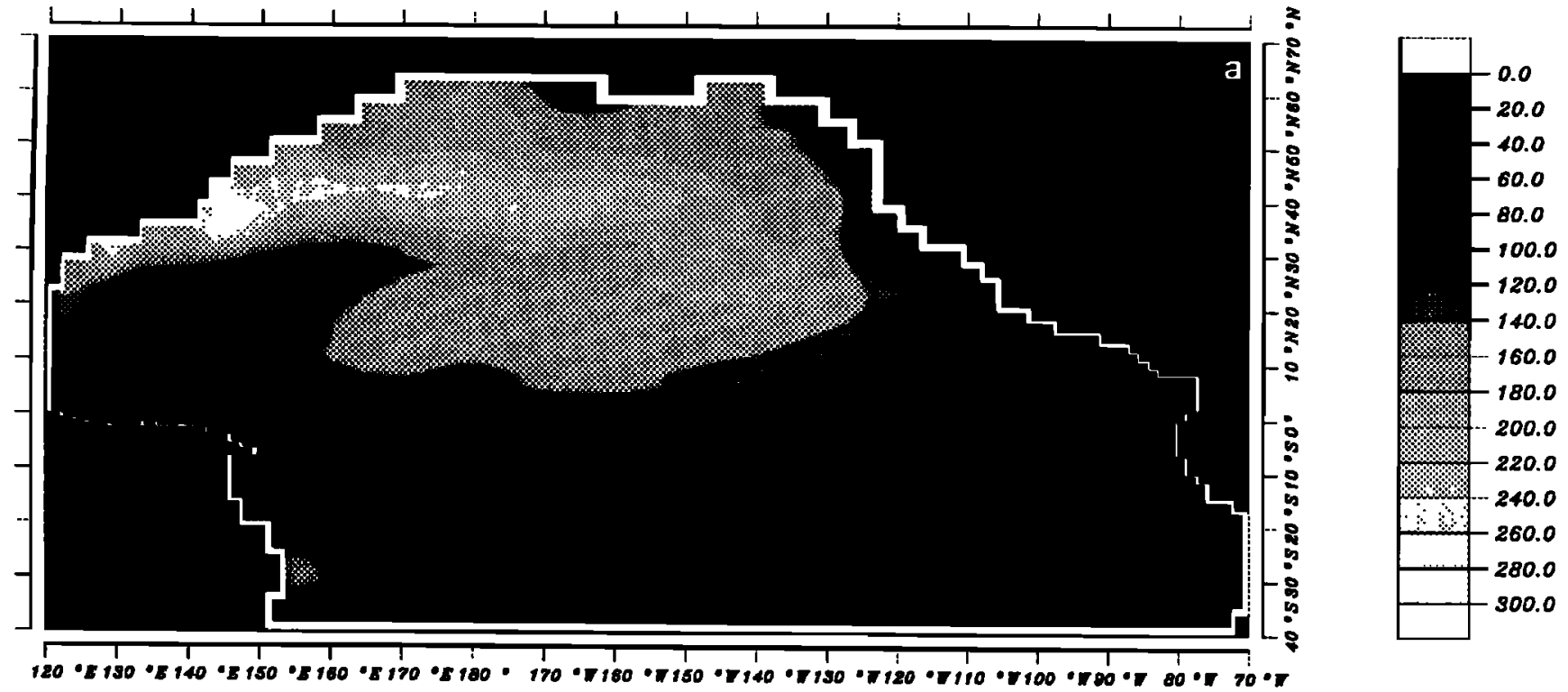

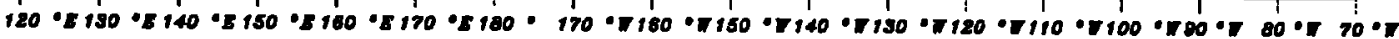
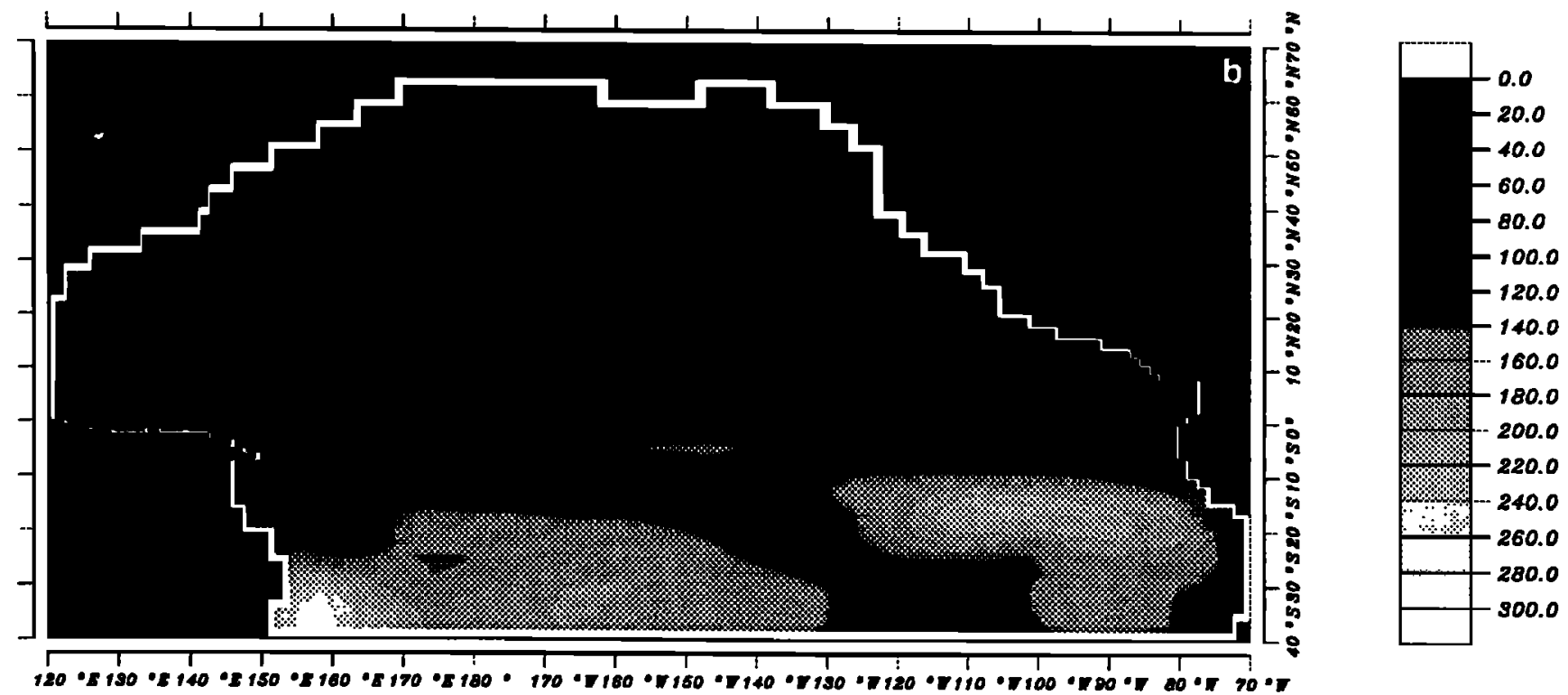

Meters

Fig. 2. Mean depth of the surface bulk mixed layer model for ( $a$ ) April and (b) October, computed from the 16-year 1970-1985 simulation (case D).

of the wind stress, which differs significantly between the FSU winds and the H-R winds.

Shown in Figure 5 are meridional cross sections of annual mean zonal currents, meridional currents, and temperature structure at $155^{\circ} \mathrm{W}$ in the model upper ocean for Case B. These results can be compared with the data from the Hawaii-to-Tahiti Shuttle experiment, which represent 1-year mean conditions between $160^{\circ} \mathrm{W}$ and $150^{\circ} \mathrm{W}$. Comparing with Figure 2 of Wyrtki and Kilonsky [1984] and Figure 6 of Luther and Johnson [1990], the model Equatorial Undercurrent has a peak zonal velocity of $44 \mathrm{~cm} \mathrm{~s}^{-1}$, which is about half of the observed. The depth of the simulated undercurrent is approximately $170 \mathrm{~m}$ compared with the observed 140 $m$. The simulated SEC does not display as much structure and asymmetry about the equator as the real current and has a maximum of only $50 \mathrm{~cm} \mathrm{~s}^{-1}$, which is weaker than the surface current estimated by Wyrtki and Kilonsky, who show peak values near $100 \mathrm{~cm} \mathrm{~s}^{-1}$. However, the model mixed layer does not resolve near-surface current shears and thus cannot be expected to have peak surface current values similar to those from ship drift observations [Richardson and McKee, 1989] or those inferred from observed dynamic 
POTENTIAL TEMPERATURE

ANNUAL MEAN CLIMATOLOGY EQ

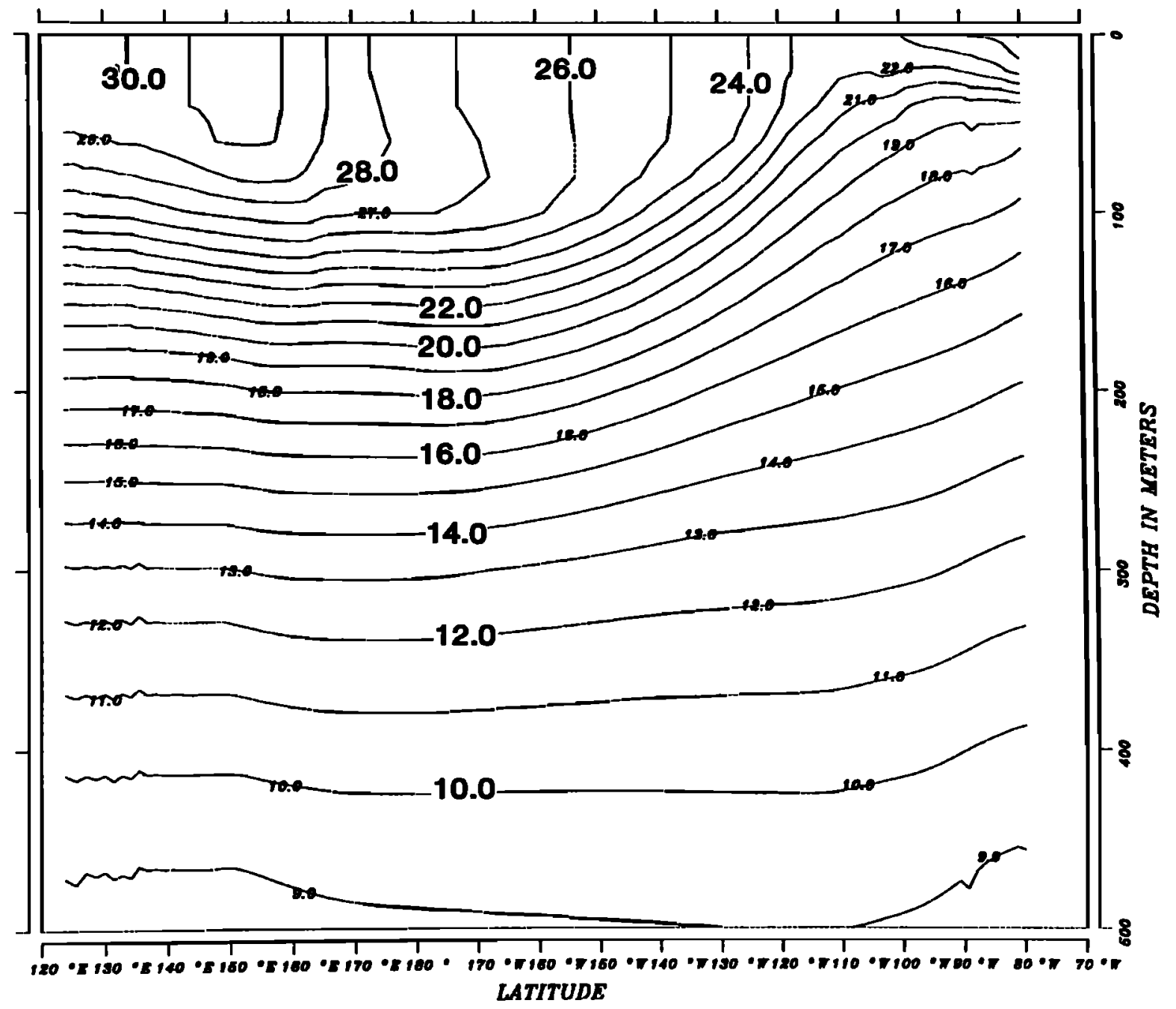

$\begin{array}{llllll}\text { REFERENCE LINE : } & 20.0 & \text { UNIT: } & \text { Celsius } & \text { MIN }=8.7 & \text { MEAN }=16.4 \\ \text { CONTOUR INTERVAL: } & 1.0 & & & M A X=30.1 & \text { STDV }=6.4\end{array}$

Fig. 3. Equatorial cross section of potential temperature computed as an average over the final year of the seasonal cycle run with FSU winds (case B).

height gradients. Noticably absent from Figure 5 is the North Equatorial Countercurrent, because in the model it is less than $10 \mathrm{~cm} \mathrm{~s}$, the lowest contour interval. Although not evident in the annual mean, the model NECC is visible in the analogous plot for October, where as was mentioned above, the maximum amplitude is only about $20 \mathrm{~cm} \mathrm{~s}^{-1}$ compared with observed values near $40 \mathrm{~cm} \mathrm{~s}^{-1}$. Gordon and Corry [1991] also found a rather weak NECC in their model (which is similar to the GFDL model) and suggested that higher latitudinal resolution could result in stronger isotherm slopes for the geostrophic flow associated with the NECC. Since OPYC is even less resolved than their model, the weaker NECC found here is consistent with their hypothesis.

It is interesting to note that in spite of the surface current field being weak and the failure of the model to represent the springtime reversal of the SEC in the eastern Pacific, the climatological SST field of the eastern equatorial Pacific is still relatively well modeled. This seems to indicate the less important role played by horizontal advection in the clima- tological near-equatorial SST budget of the eastern Pacific compared with surface heat fluxes and vertical advection as found by Seager et al. [1988] in the heat budget of their relatively simple model. Harrison [1992], in contrast, finds that meridional advection plays a vital role in the surface heat budget of that region of the GFDL model.

\subsection{Vertical Velocity}

The mean vertical velocity along the equator for case $B$ is shown in Figure 6 and exhibits the expected upwelling pattern in the central region of the Pacific. The peak upwelling there is approximately $6 \mathrm{~m} \mathrm{~d}^{-1}$, which is somewhat larger than that found in the GFDL model by PHS87 (their Figure 4). This present model also has relatively strong upwelling at depth, which is in contrast to the GFDL response which peaks at $50 \mathrm{~m}$ depth and tails off to near zero at $200 \mathrm{~m}$ depth. In the western Pacific, the present model shows strong downwelling ( $5 \mathrm{~m} \mathrm{~d}^{-1}$ peak) in the region of the 


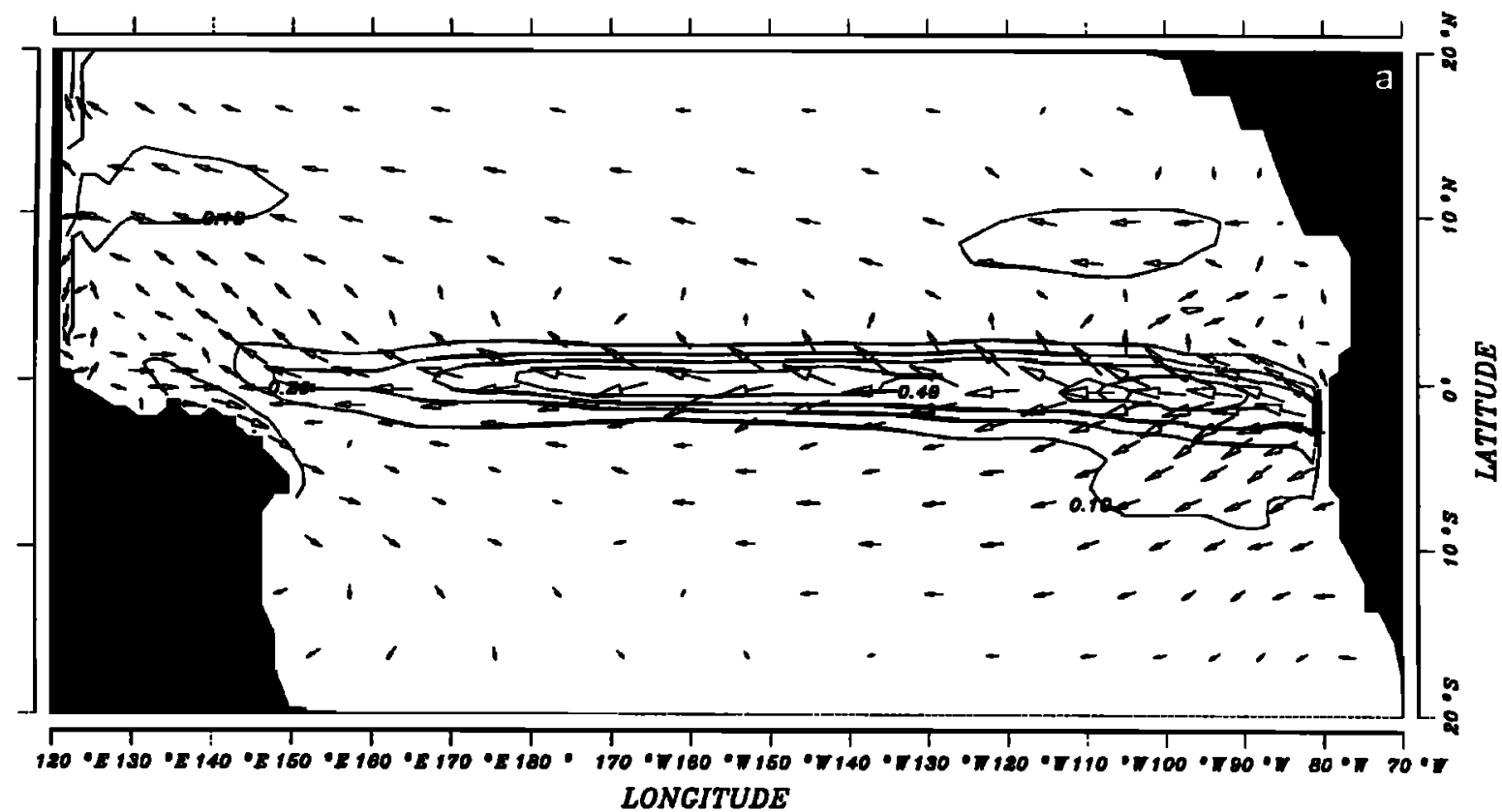
UNIT :
$M / S$
$M I N=0.00$
$M E A N=0.08$
CONTOUR INTERVAL:
0.10
$M A X=0.47$
$S T D V=0.10$

\section{VELOCITY FIELD}

\section{Oct Model Mean}

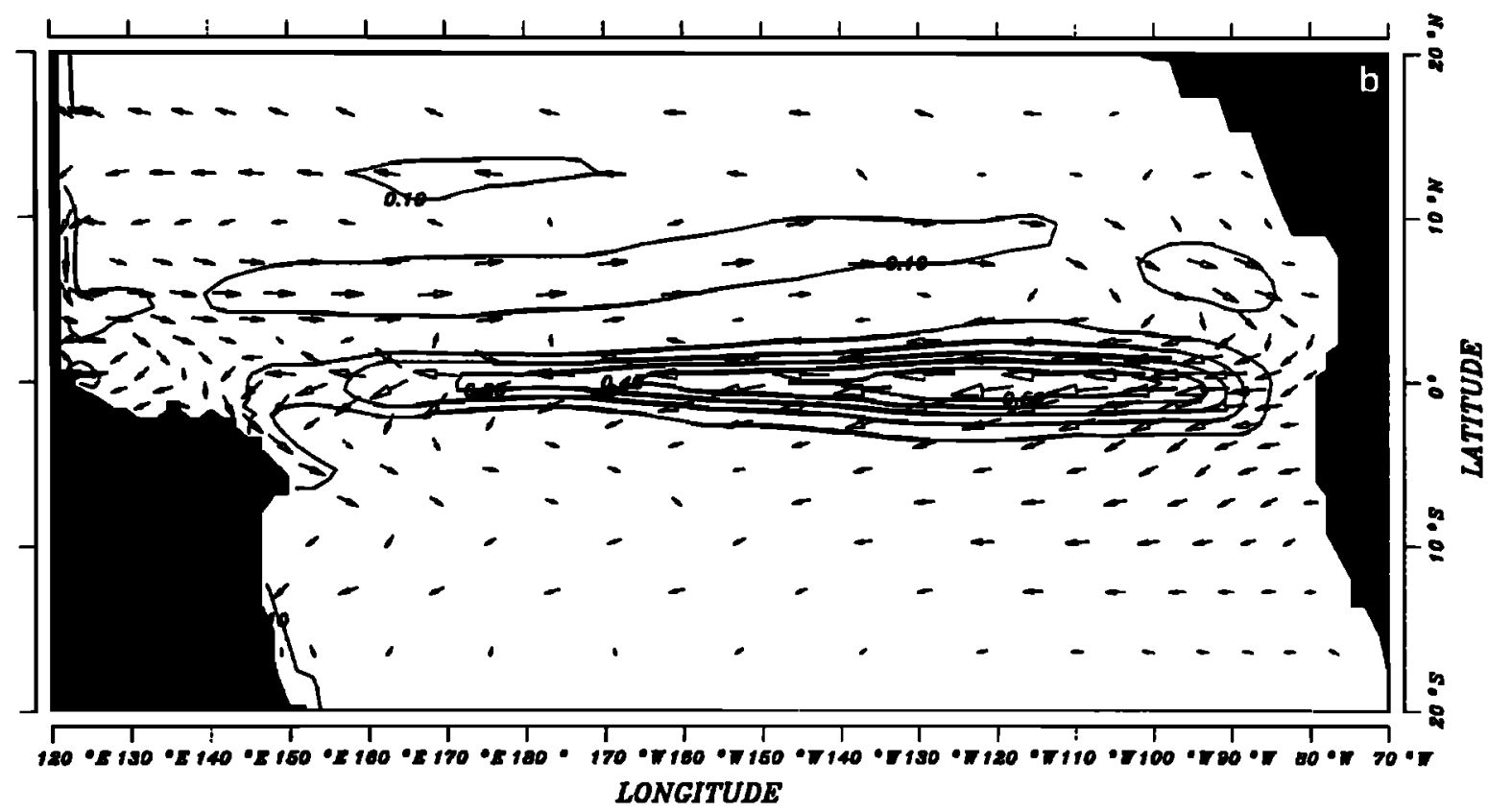

$\begin{array}{llll}\text { UNIT : } & W / S & \text { WIN }=0.00 & \text { YEAN }=0.08 \\ \text { CONTOUR INTERVAL: } & 0.10 & \text { MAX }=0.69 & S T D V=0.10\end{array}$

Fig. 4. Mean currents of the surface bulk mixed layer model for ( $a$ ) April and $(b)$ October, computed from the 16-year 1970-1985 simulation (case D).

warm pool, which is consistent with the deep thermocline there. This feature is different from the simulation of PHS87 in which strong upwelling along the equator is closed by downwelling north of the equator, i.e., a north-southcirculation cell. The OPYC mean response exhibits upwelling in the central/eastern Pacific closed by downwelling in the warm pool region, i.e., an east-west circulation cell. It is difficult to verify which of the two scenarios are closer to reality because of the extreme difficulty in determining vertical velocity from observations. (Passive tracer distribu- 

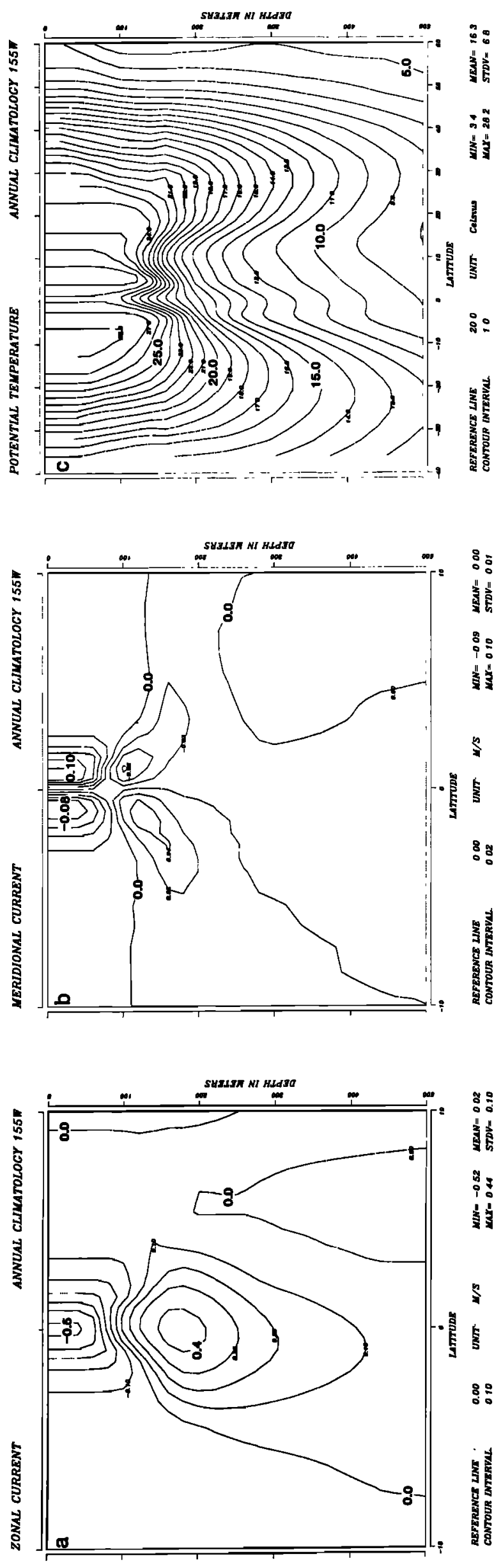

tions in the warm pool region would be helpful in determining whether significant downwelling is actually occurring there.) However, Halpern et al. [1989] estimated vertical velocity from the divergence of an equatorial current meter array along the equator. Between $140^{\circ} \mathrm{W}$ and $110^{\circ} \mathrm{W}$, for a nearly 1 -year mean, they found an ensemble mean of $190 \mathrm{~cm}$ $\mathrm{d}^{-1}$ for all estimates between 25 and $120 \mathrm{~m}$ depth, which is more comparable to the PHS87 results than those of OPYC. Also, the data appeared to indicate [Halpern et al., 1989, Figure 1] that the signal was decreasing with depth in a manner more similar to PHS87 than OPYC.

\subsection{Summary of Climatological Response}

The climatological response of the model appears to be fairly comparable to that of other models with similar dynamical complexity, although there are clearly deficiencies in the model's simulation. It does relatively well in accounting for the observed mean SST structure, but the model thermocline structure is too diffuse, particularly the subthermocline structure in the eastern Pacific. This model also generates a physically plausible MLD climatology and an upper ocean upwelling field which, though too strong, exhibits a unique downwelling structure in the western Pacific warm pool region. Finally, the model reasonably simulates the observed seasonal structure of the horizontal velocity field, although the amplitude is too small and the springtime reversal of the South Equatorial Current in the eastern Pacific is absent. Thus our first attempt to apply an isopycnic coordinate general circulation model to equatorial circulation suggests a promising future for this model. In the following section we examine some of the model processes responsible for tropical ocean variability.

\section{Anomalous Response}

In this section, we examine the tropical ocean variability in case D (1970-1985 run forced by FSU winds). The anomalous model response in sea level, currents and SST is compared with observations as well as the results from other published simulations.

\subsection{Sea Level}

The anomalies in sea level at several tropical tide gauge stations are shown in Figure 7 for observations and for case $\mathrm{D}$, relative to the monthly mean climatology of case $\mathrm{C}$. The response in the western Pacific, which may be described as a local response to the highly variable winds there (Davao, on the western boundary, and Truk Island in the western Pacific), is better represented than the remote response (Christmas Island and Callao), which primarily relies on the dynamics of wave propagation for the largest component of the signal. The eastern Pacific response is smaller relative to the observations than is the response in the western Pacific (as was found, for example, by Graham et al. [1989]), even though the changes in sea level due to thermal expansion and the effects of a zonally varying thermocline depth are included. The sea level anomalies in this model tend to have comparable amplitudes (but different detailed structure) to those from the FSU [Busalacchi et al., 1983] reduced gravity shallow-water model (indicated in Figure 7 where available) and the L87 model, which were both forced by essentially the same wind fields as OPYC. The present model, however, exhibits a long-term trend in sea level, a rising of about $20 \mathrm{~cm}$ from 1961 to 1985 (Figure 7), which can be explained by a 


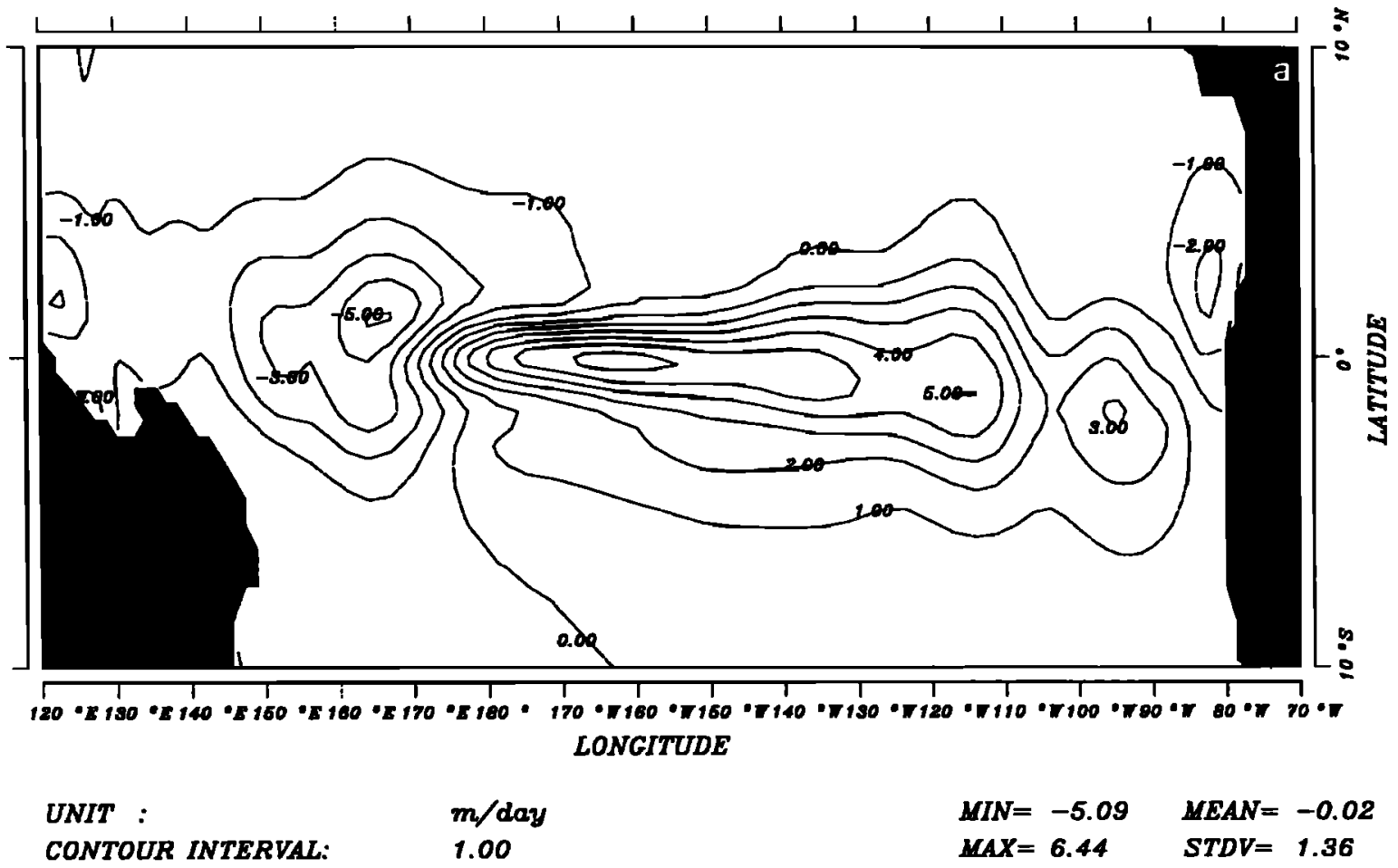

\section{VERTICAL VELOCITY}

\section{CLIMATOLOGY 25OM MEAN}

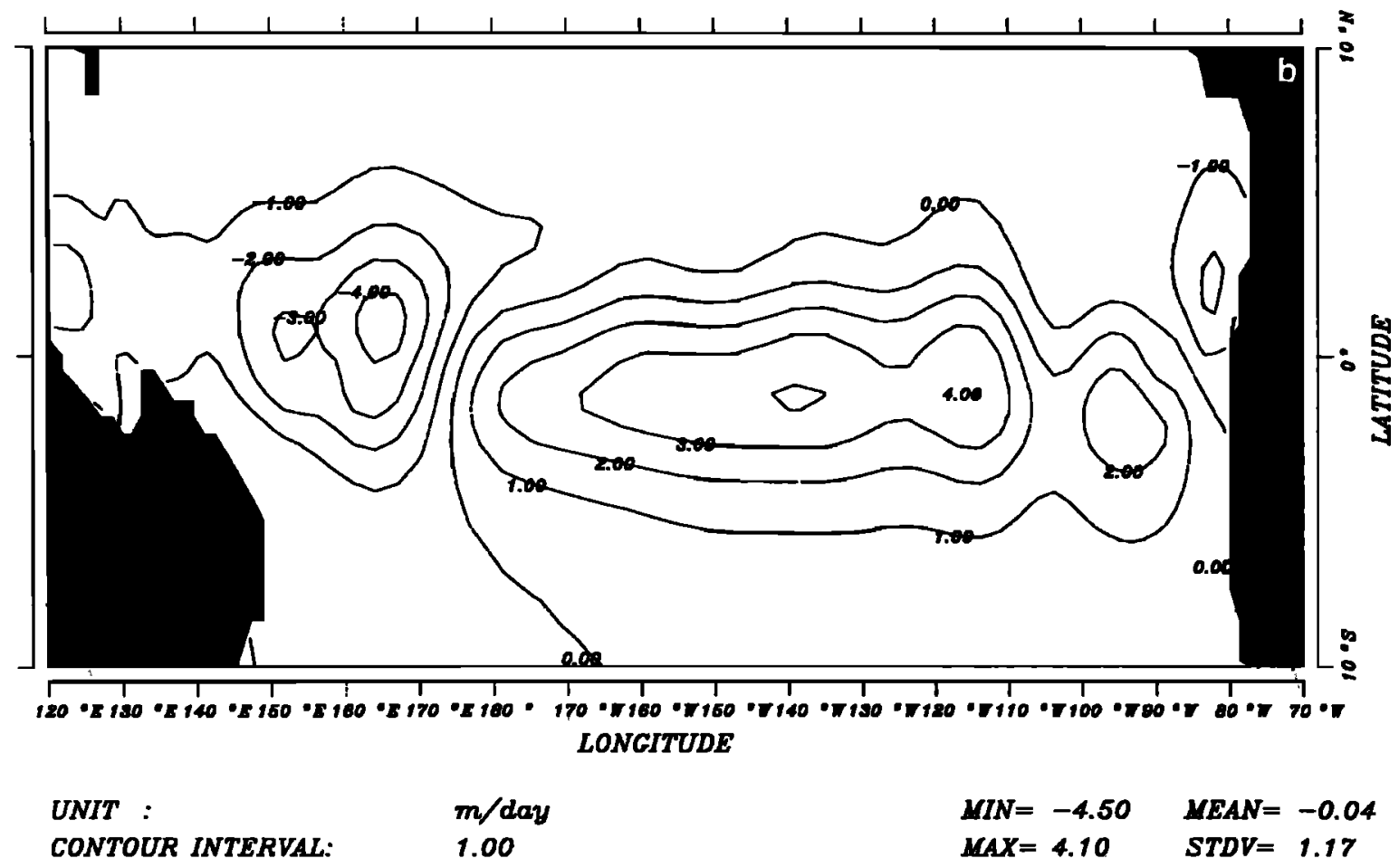

Fig. 6. Annual mean vertical velocity at (a) $100 \mathrm{~m}$ depth and (b) $250 \mathrm{~m}$ depth computed as an average over the final year of the seasonal cycle run with FSU winds (case B).

slow warming and slight freshening of the water column and the ensuing expansion, during the simulations. This arises primarily because the source of deep water formation in the high southern latitudes is excluded from the model.

\subsection{Currents}

The velocity anomalies in the surface mixed layer tend to be weaker than those shown in other models and in obser- 

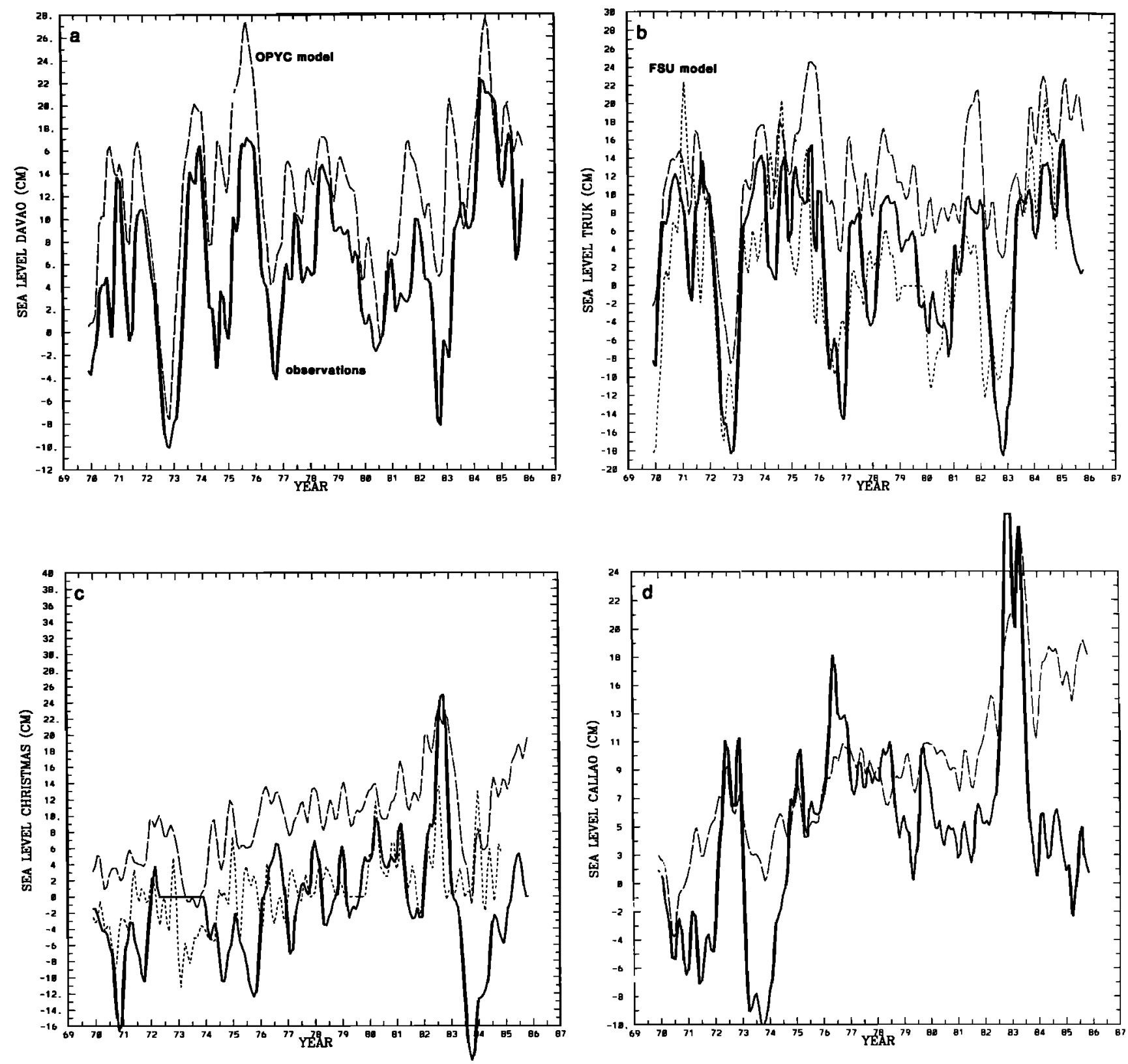

Fig. 7. Sea level anomalies for several tide gauge stations in the Pacific: (a) Davao $\left(7^{\circ} \mathrm{N}, 126^{\circ} \mathrm{E}\right),(b)$ Truk $\left(7^{\circ} \mathrm{N}\right.$, $\left.152^{\circ} \mathrm{E}\right),(c)$ Christmas Island $\left(2^{\circ} \mathrm{N}, 157^{\circ} \mathrm{W}\right)$, and $(d)$ Callao $\left(12^{\circ} \mathrm{S}, 77^{\circ} \mathrm{W}\right)$. Sea level anomalies of the $1970-1985$ run (case D) at the nearest grid point to the island, relative to the climatological monthly mean sea levels of the 1961-1973 run (case C), are indicated by the long-dashed lines. Observed sea level anomalies, relative to a long-term climatological monthly mean climatology, are indicated by the solid lines. At the available stations, sea level anomalies (related to the thickness of a shallow-water surface layer and averaged over a $4^{\circ}$ box rather than a single point) from the FSU model [Busalacchi et al., 1983] are indicated by the short-dashed lines (the FSU model data for 1979 are missing).

vations. For example, zonal current anomalies averaged over the entire Niño-4 or Niño-3 regions (not shown) have typical peak amplitudes of the order of $5-10 \mathrm{~cm} \mathrm{~s}^{-1}$. Although these velocity anomalies are difficult to verify because few observations are available over extended time intervals, the simulated anomalies are certainly weaker than observed surface current anomalies. As was noted earlier, the prime reason for this is that the bulk mixed layer predicts depth-integrated currents, while observed currents are often surface intensified even in the mixed layer [e.g., Firing et al., 1983].

One example of an extended time series of equatorial currents was published by Halpern [1987]. Figure 8 shows that the model zonal current variability at the grid point nearest $110^{\circ} \mathrm{W}$ on the equator compares relatively well with the monthly mean observations. In contrast, the model meridional current variations appear to be almost uncorrelated to the monthly mean observations, probably a consequence of 20-day waves being the overwhelming signal (approximately $50 \mathrm{~cm} \mathrm{~s}^{-1}$ amplitude) in the daily observations [Halpern, 1987]. Similar results were found by L87 in comparing his model with these observations. Figure 8 also shows that the mean zonal current of the model is biased toward westward flow compared to the Halpern observations. These observations exhibit weaker westward flow than the ship drift observations of Richardson and McKee 

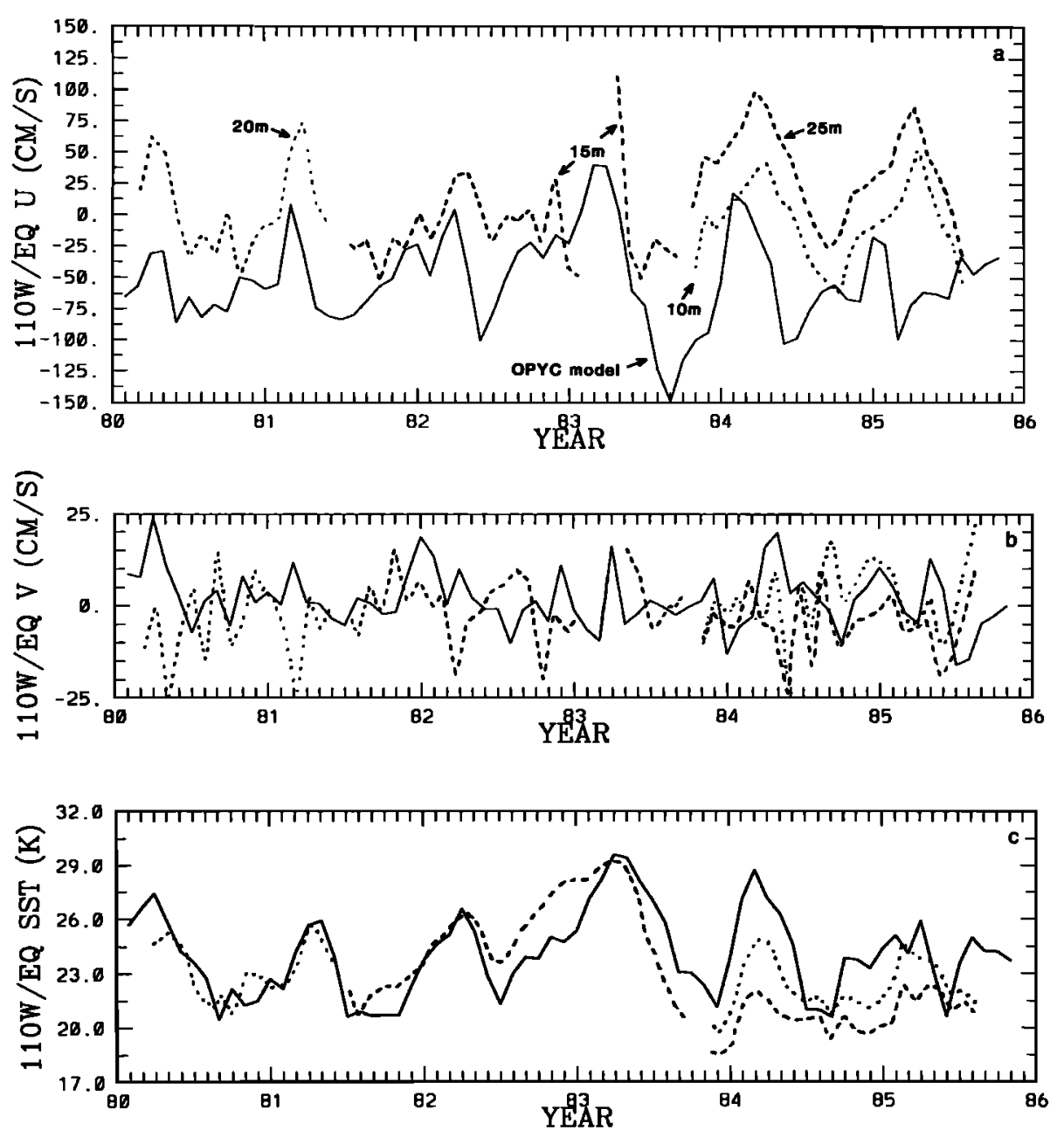

Fig. 8. Monthly mean values of model and observed fields at $\left(0^{\circ}, 110^{\circ} \mathrm{W}\right)$ of $(a)$ zonal current, $(b)$ meridional current, and $(c)$ temperature. Model values are from the surface mixed layer model for case $\mathrm{D}$ and are indicated by a solid line. Observed values, extracted from Halpern [1987], are indicated by dashed lines, the first segment for $20 \mathrm{~m}$ depth, the second and third segments for $15 \mathrm{~m}$ depth, and the contemporaneous final segments for $25 \mathrm{~m}$ (dashed) and $10 \mathrm{~m}$ (dotted) depth.

[1989], which indicate westward flow throughout most of the annual cycle [McPhaden et al., 1991]. Other models [L87; PHS87; Harrison, submitted] also exhibit a stronger westward flow in the vicinity of $110^{\circ} \mathrm{W}$ than do the Halpern current meter measurements.

\section{3. $S S T$}

The modeled and observed anomalous SST response is shown in Figure 9 for the so-called Niño-4, 3, and 2 regions of the tropical Pacific. In the western Pacific (Niño-4), where the greatest variability of wind occurs, the SST response may be termed "local" and the model results compare well with observations (correlation coefficient of 0.70 ). In the eastern region of the basin (Niño-3), where remotely generated baroclinic wave activity is thought to be responsible for a substantial part of the response, there is also a fairly realistic response in SST with a correlation of 0.69. But in the Niño-2 region (off the coast of Ecuador), which (as is suggested in section 5.4 below) relies more on the effects of anomalous vertical mixing, the correlation drops to 0.47 . A weak point of the model SST response is that the magnitude of the cold episodes are underpredicted. The verisimilitude of the anomalous warm SST events appears to be compara- ble to that of the warm events simulated by S89, but the present model's cold events are less realistic. B. Giese (private communication, 1991) forced a low-resolution version of the GFDL model with FSU winds and found that the anomalous SST was remarkably similar to thatof OPYC in the Niño-4 and -3 regions, suggesting the strong model dependence on the specifics of wind stress variability [Harrison et al., 1989].

Color movies were also employed to compare modeled and observed SST anomaly time series. It is clearly evident from viewing these clips that the detailed spatial structure of SST anomalies during El Niño events is poorly matched to the structure of observations (for example, the 1982-1983 event discussed in section 5 and depicted in Figure 10). We therefore examined the rms error and anomaly correlation on a point-by-point basis. The results were poor for unsmoothed fields, as we expected, since we have no information on the high-wavenumber structures of the forcing field. To test the low-wavenumber performance of the model's SST simulation, we smoothed the model (and data) with spatial filters until the pointwise correlations were comparable to those between time series in the Niño regions; in general, greater spatial averaging was found to improve the correla- 

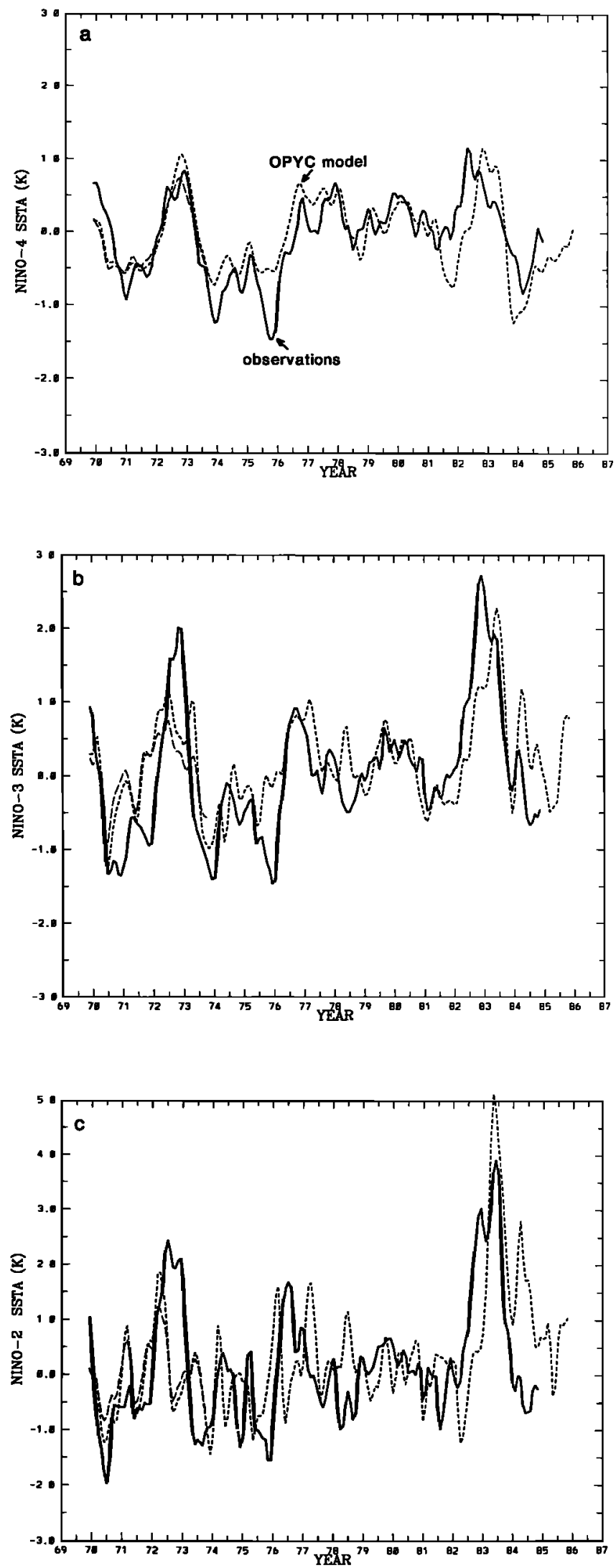

Fig. 9. SST anomalies from case D, relative to the monthly means of case $\mathrm{C}$, averaged over $(a)$ the Niño- 4 region $\left(160^{\circ} \mathrm{E}\right.$ to $150^{\circ} \mathrm{W} ; 5^{\circ} \mathrm{N}$ to $\left.5^{\circ} \mathrm{S}\right),(b)$ the $\mathrm{Ninno}-3$ region $\left(150^{\circ}-90^{\circ} \mathrm{W} ; 5^{\circ} \mathrm{N}\right.$ to $\left.5^{\circ} \mathrm{S}\right)$, and $(c)$ the Niño-2 region $\left(90^{\circ} \mathrm{W}\right.$ to coast; $0^{\circ} \mathrm{N}$ to $\left.5^{\circ} \mathrm{S}\right)$, indicated by the dashed line. Observations, relative to a long-term monthly mean climatology, from the COADS are indicated by the solid line. The correlation between model and observed anomalies in the three plots are $0.70,0.69$, and 0.47 , respectively. tions. It is difficult to compare such results with other published works because the detailed spatial structure of modeled SST is seldom discussed. Therefore we are presently analyzing the detailed processes of El Niño evolution in several ocean models which we have run for the 1970-1985 time interval; these results will be discussed in a separate publication.

The variability of the OPYC model SST near the date line is too large, as is revealed by a large local maximum there in maps of rms SST error (also evident in Figure 10). This is apparently due to the model thermal structure's being too diffuse in the western Pacific (a common problem of tropical circulation models) and is exacerbated by the shallow turbulent mixed layer there (due to weak TKE input). Future versions of this model must have a sharper thermocline in the warm pool region to counteract this effect.

\section{The 1982-1983 El NiÑO}

Since a great deal of interest lies in the extremely anomalous response of the tropical ocean during the 1982-1983 El Niño, we discuss the simulated response for that year in some detail.

\section{1. $S S T$}

The general character of the anomalous SST response in 1982-1983 can be seen in Figure 9, which shows time series of observed and simulated anomalous SST in the Niño-4, -3 and -2 regions. In the western Pacific (Niño-4) the amplitude of the model response is comparable to observations, but during the 1982-1983 event, the model response lags the observed by about 6 months. B. Giese (private communication, 1991) found a very similar phase-lagged response for 1982-1983 in the GFDL modular ocean model which leads us to believe that part of the problem is due to errors in the common wind field which drives the models. In the eastern Pacific (Niño-3) the anomaly develops slower in the model than in observations and again peaks about 6 months after the observed peak. These types of features seem to be common to models forced by FSU winds; for example, S89's Figure $1 d$ shows a similar response in the eastern Pacific during the 1982-1983 event. In the Niño-2 region, off the coast of Ecuador, the maximum 1982-1983 anomaly is somewhat too large, and the model does not reproduce the double-peak structure of the observations. In addition, the eastern Pacific model response exhibits a secondary warming in early 1984, which does not appear in the observations.

Figure 10 shows a time sequence of SST anomaly maps for both model and the COADS observations during the 19821983 event. The late appearance of warm water (particularly clear in the eastern Pacific) and the excessively high amplitude of SST in the latter months of the event are evident in these plots. The model SST tends to be much too confined to the equatorial band ( $\pm 5^{\circ}$ latitude) compared with the data. This may be due to the model's relying solely on ocean dynamics to generate the SST anomalies, with heat flux anomalies serving only to dampen SST anomalies. In contrast, the model of S89, which allows heat fluxes to possibly drive anomalies, exhibits equatorial SST anomalies with greater poleward extent, more similar to those observed. But the verifying SST observations themselves have data gaps in space and time and have been heavily smoothed to produce the maps shown here. This smoothing/interpolation will make the smoothed SST anomaly appear more meridionally diffuse than it may actually be. The corresponding maps of 
SEA SURFACE TEMPERATURE

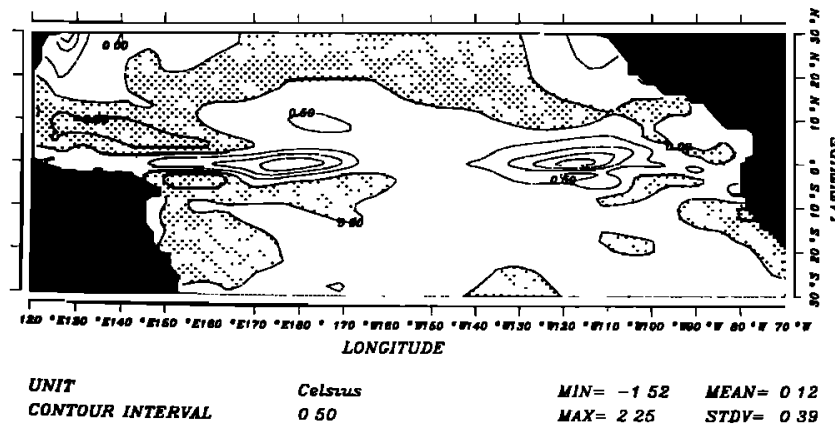

SEA SURFACE TEMPERATURE

Nov 82 Model Anomaly

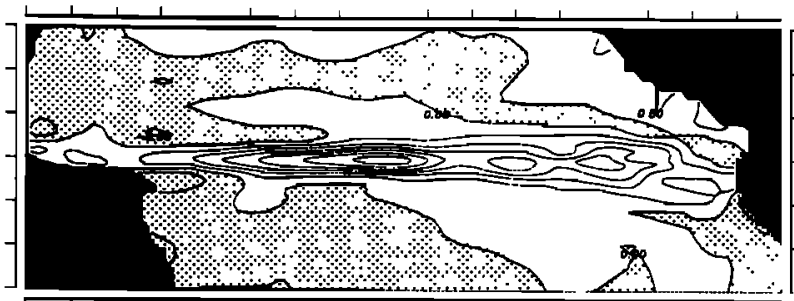

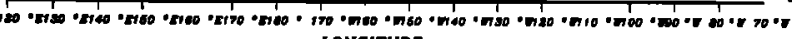
LONGITUDE

$\begin{array}{llll}\text { UNIT : } & \text { CoLSiuS } & \text { WIN }=-0.96 & \text { YEAN= } 0.28 \\ \text { CONTOUR INTERVAL: } & 0.50 & \text { WAX }=330 & \text { STDV= } 0.66\end{array}$

a

SEA SURFACE TEMPERATURE

Aug 82 Coads Anomaly

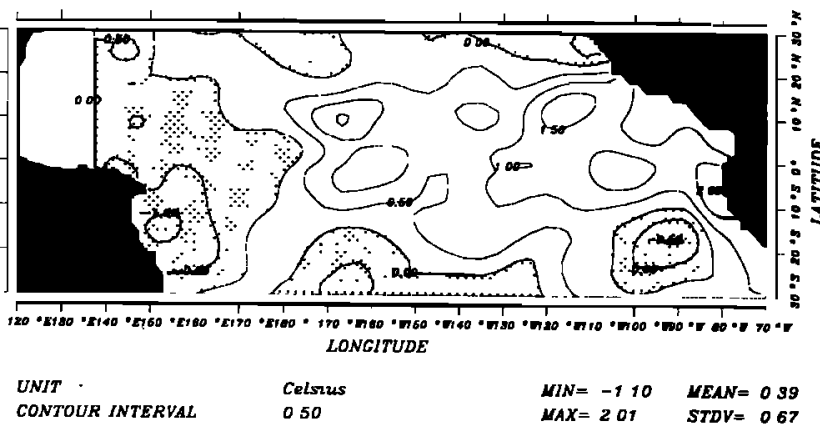

b SEA SURFACE TEMPERATURE

Nov 82 Coads Anomaly

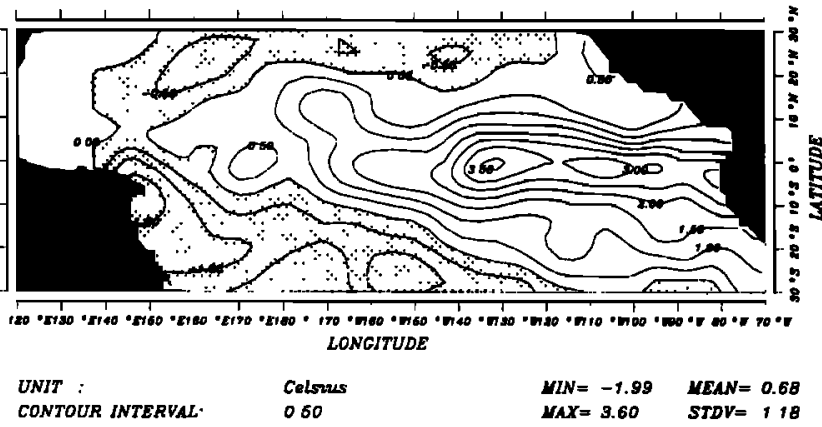

C SEA SURFACE TEMPERATURE

Feb 83 Coads Anomaly
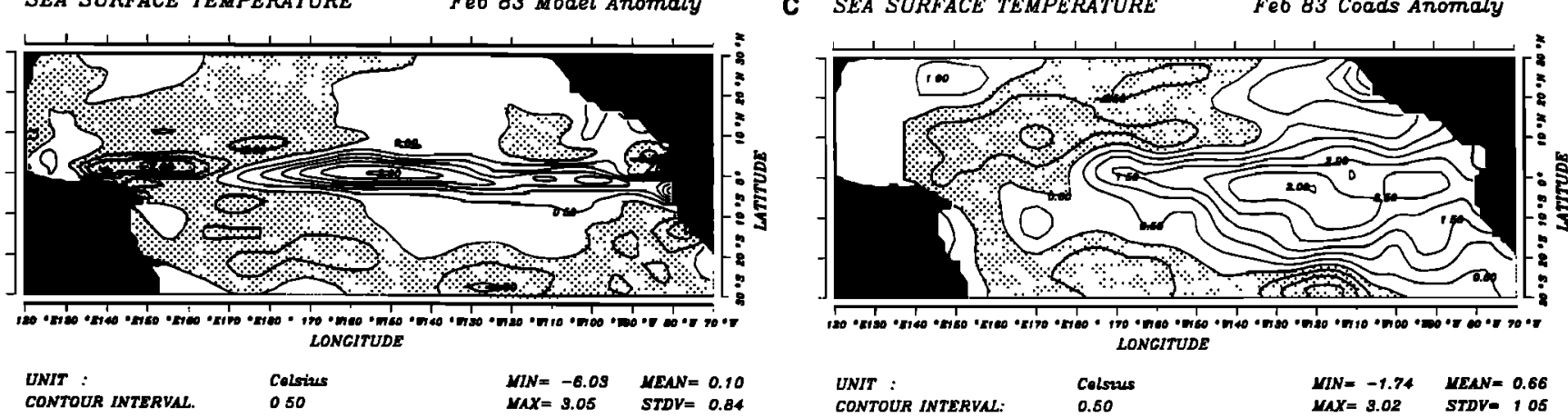

d SEA SURFACE TEMPERATURE

Apr 83 Coads Anomaly

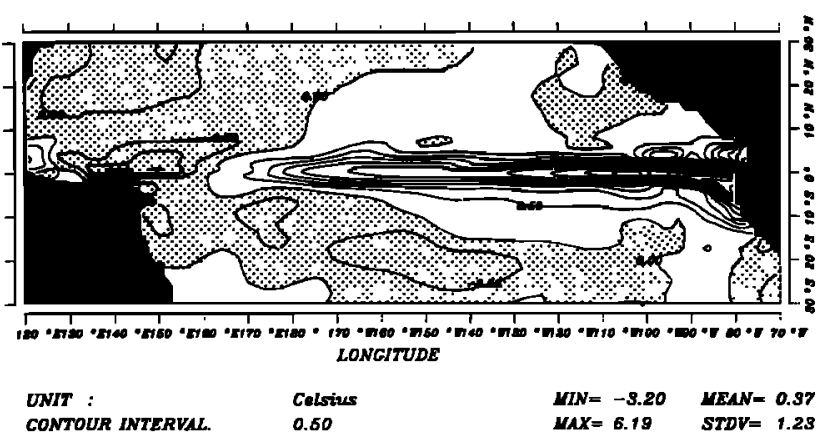

Fig. 10. SST anomalies for (left) case D and (right) COADS observations for (a) August 1982, (b) November 1982,

(c) February 1983, and (d) April 1983. Stippled regions indicate negative anomalies.

Jia et al. [1990, Figure 4], who forced a model similar to the GFDL model with FSU winds, show model SST anomalies with structure in the open ocean which is remarkably similar to those seen in Figure 10. The primary differences in their response are that their open-ocean SST anomalies have larger amplitude than those from OPYC (Figure 10) and the response adjacent to the Ecuadoran and Peruvian coasts in their model is weaker than in OPYC and in observations. 


\subsection{Velocity}

The surface velocity field during October 1982 and April 1982 is shown in Figure 11 along with the anomalous currents during those months. The strong reversal of flow (from the climatologically westward currents) along the equator in the western Pacific during October 1982 and in the eastern Pacific during April 1983 is evident. The structure of the currents is similar to the GFDL simulation (Figure 10 of PS85) except in April 1983, when the present model shows a strong westward flow along the equator which is not evident in PS85. The central Pacific current anomaly in October 1982 and the eastern Pacific current anomaly in April 1983 can be associated with (different) downwelling Kelvin waves (see Figures 13 and 14).

Another perspective of current variability is provided by Figure $12 a$, which shows velocity versus time and latitude at $162^{\circ} \mathrm{W}$. This figure can be compared directly with Figure 19 of PS85 and Figure 15 of L87, with the most pronounced difference being the lower current speeds in the OPYC response. As was stated previously, this is primarily due to OPYC's "surface" current corresponding to the average over the mixed layer rather than the current at the 5- or 10-m depth grid point; PS85 show the 95-m-depth velocity field which in many regions has considerable shear with respect to the $5-\mathrm{m}$ velocity. The basic structure of the model response is, however, similar to PS85 and L87; a sharp current reversal occurs in mid-1982 followed by a resurgence of westward flow in early 1983.

The variability of the Equatorial Undercurrent can be seen in Figure $12 b$, which shows equatorial zonal current profiles during $1982-1983$ at $162^{\circ} \mathrm{W}$; this figure can be directly compared with S86 and L87 as well as with the observations of Firing et al. [1983]. Again, OPYC tends to underpredict the size of the current field. The undercurrent has a maximum of $50 \mathrm{~cm} \mathrm{~s}^{-1}$ in early 1982 compared with $70 \mathrm{~cm} \mathrm{~s}^{-1}$ for L87 and $100 \mathrm{~cm} \mathrm{~s}^{-1}$ for PS85 and the observations. The present model shows the undercurrent disappearing by the end of September 1982 and recovering fully by June 1983, while the observations indicate that the drop-off in portions of the undercurrent speed lasted from August 1982 through January 1983, recovering fully by March 1983 .

\subsection{Relations Between Variables}

An overview of the events taking place during 1982-1983 is shown in the time series of zonal variations along the equator for current, SST, MLD, and the depth of the $20^{\circ} \mathrm{C}$ isotherm and their anomalies (Figures 13 and 14). (We note again that the MLD is forced by climatological TKE input, so that the mixed-layer entrainment variations respond only indirectly to variable winds through SST, currents, and heat fluxes.) Evidence of rapid eastward propagation due to baroclinic Kelvin wave propagation [e.g., McCreary, 1976; Barnett et al., 1991] can be seen in the thermocline and zonal current fields. The zonal current variability (Figure 13a) is remarkably similar (except for the weakness of the flows) to that of the models of L87 and Jia et al. [1990] (which are also forced by FSU winds) and also quite similar even to the PS85 simulation (forced by NMC winds). The eastward zonal current anomaly which begins in the western Pacific in mid-1982 is associated with downwelling, as evidenced by the deeper mixed layer in the central Pacific in late 1982 and the increased depth of the $20^{\circ} \mathrm{C}$ isotherm in the eastern Pacific from late 1982 through mid-1983.
It is clear that there is a strong resemblance between the zonal current and the SST variability in Figure 14, suggesting that zonal advection contributes significantly to SST variability in the model (see section 5.4 for further discussion of this point). However, it is also interesting to compare the structure of the surface mixed-layer anomalies (Figure 14c) with anomalies of SST (Figure 14b) and anomalous depth of the $20^{\circ} \mathrm{C}$ isotherm (Figure $14 d$ ). During much of the 19821983 time span, the SST anomalies of the eastern Pacific are better correlated with the anomalies of the depth of the $20^{\circ} \mathrm{C}$ isotherm than with the MLD anomalies. This suggests the importance of upwelling effects on SST variability in that region (see section 5.4). This also lends support to the shallow-water models [e.g., Busalacchi et al., 1983] which specify SST anomalies in terms of anomalies in the depth of the surface shallow-water layer. In contrast, in the central Pacific during the height of the 1982-1983 event, the SST anomalies are better correlated with MLD anomalies than with thermocline anomalies, suggesting that upwelling effects are less important there. The sudden decrease in MLD in the western Pacific in January 1983 can be associated with surface layer cooling by anomalous entrainment, a feature which is confirmed in the next section.

\subsection{Heat Budget of the Surface Mixed Layer}

The mechanisms which influence SST anomalies in this model (equation (2)) are horizontal advection, vertical mixing (through variations in entrainment velocity and entrained fluid), surface heat flux, and horizontal diffusion. We have computed the monthly-mean climatology of those four terms for case D so that we are able to examine the anomalous effects of the four terms. Figure 15 shows anomalous monthly mean terms in the heat budget for the 1982-1983 time period for the Niño-4, -3 and -2 regions (corresponding to the SST anomalies in the 1982-1983 time period in Figure 9). In all three regions, horizontal diffusion is weak, which indicates that model dynamics rather than eddy diffusion parameterizations are dominating the response.

In the western Pacific (Niño-4), anomalous advection excites the SST anomalies, which is consistent with visual inspection of the maps of surface velocity shown in Figure 11, the diagnostics of other wind-forced models [PS85, L87, S89, Harrison et al., 1990, Barnett et al., 1991] and observations of the 1986-1987 El Niño event [McPhaden and Picaut, 1990]. Subsequently, the warm anomalies are damped, alternately by heat flux (which always serves to dampen the anomalies in the model [cf. S89; Barnett et al., 1991]) and two episodes of anomalously strong vertical mixing, followed by the development of a cold episode through anomalous advection in late 1983.

In the eastern Pacific (Niño-3), horizontal advection and anomalously weak mixing both contribute to the growth of the SST anomalies until late 1983, when they both contribute to the demise of the warm event. Off the South American coast (Niño-2), anomalously weak mixing, due to a depressed thermocline, plays the major role in the warming of SST (in line with S89 and Barnett et al. [1991]), though horizontal advection also contributes significantly. In both these regions, during the height of the warm event only the heat fluxes serve as a cooling mechanism. The mean heat flux for the May 1982 to May 1983 interval (plotted in Figure 16b) shows that the overall heat flux was reduced by approximately 


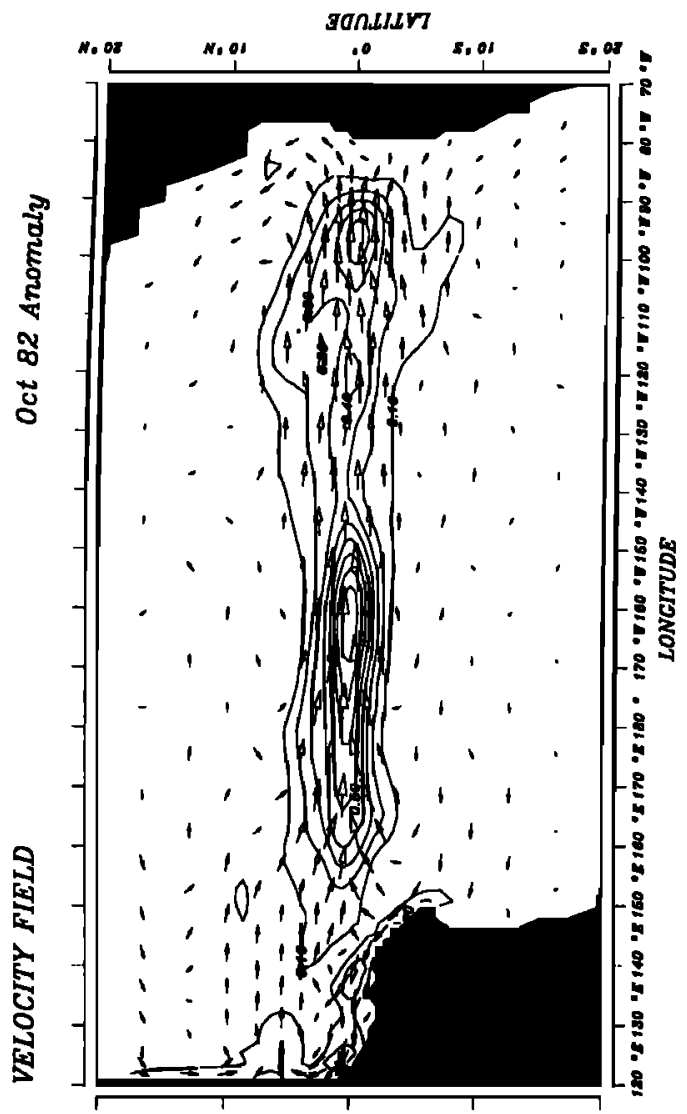

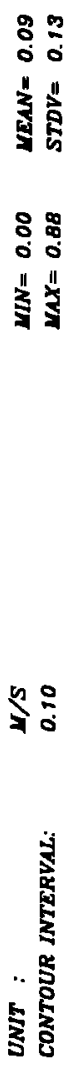

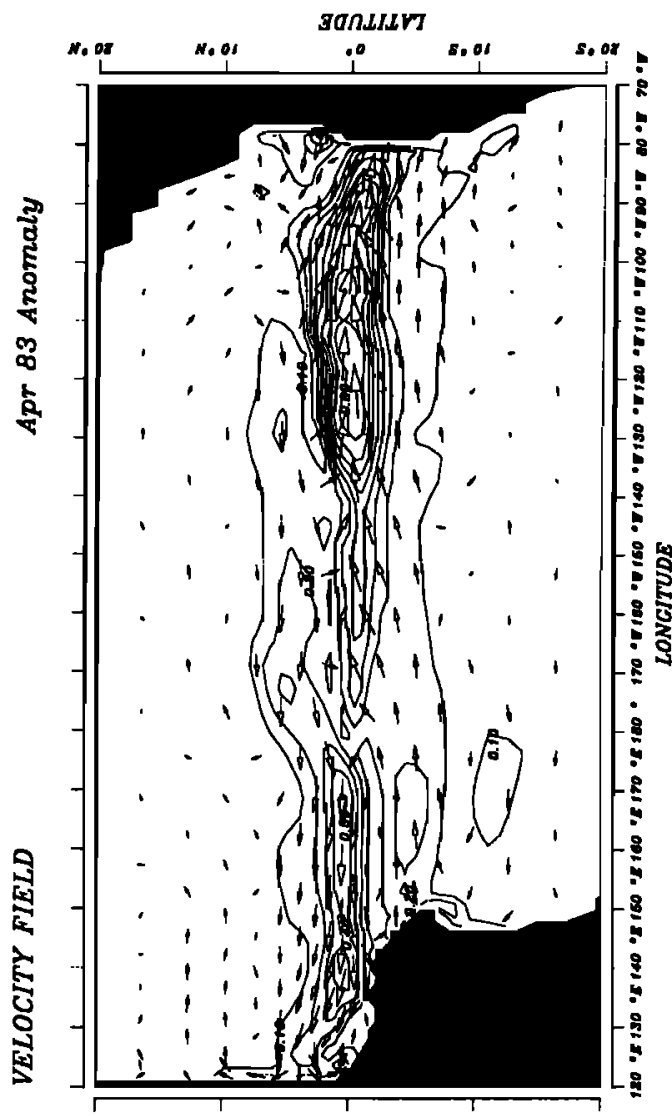

$\frac{\infty}{0}$

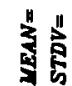

$8:$

בั

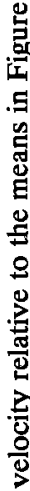

농

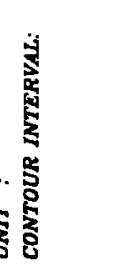

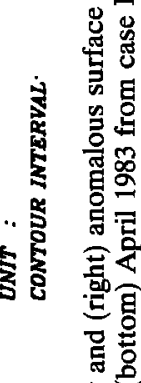

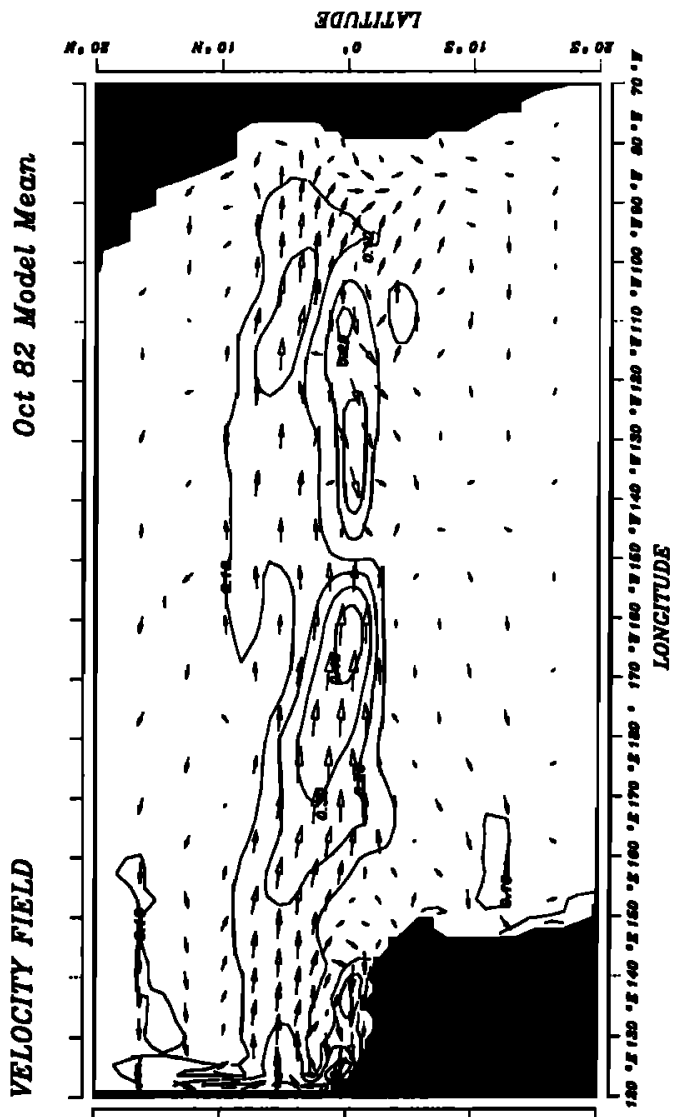

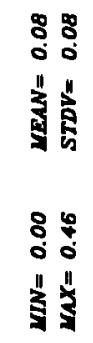
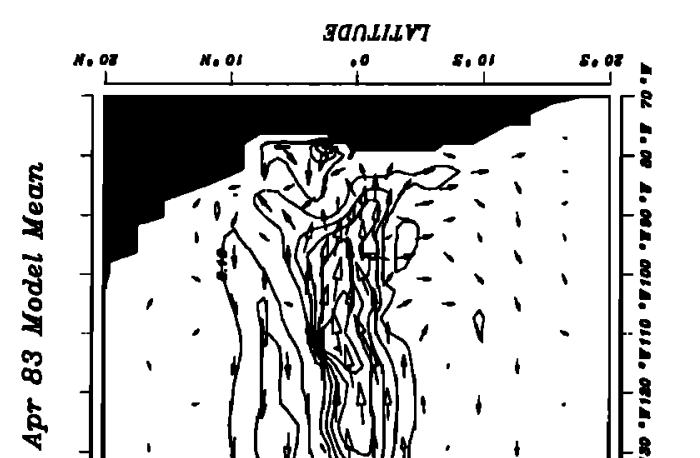

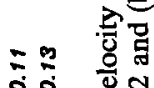

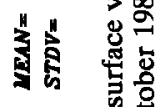

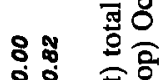

i 0 :

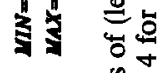

象

ำㅇํㅇ



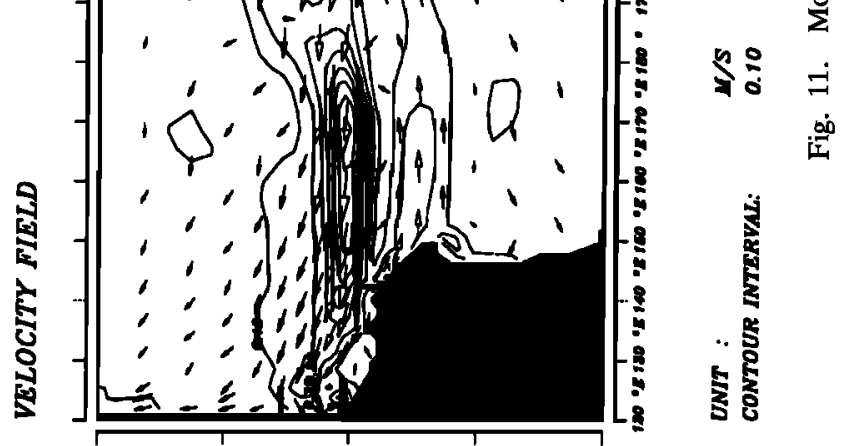

$\sum \frac{1}{0}$

总 


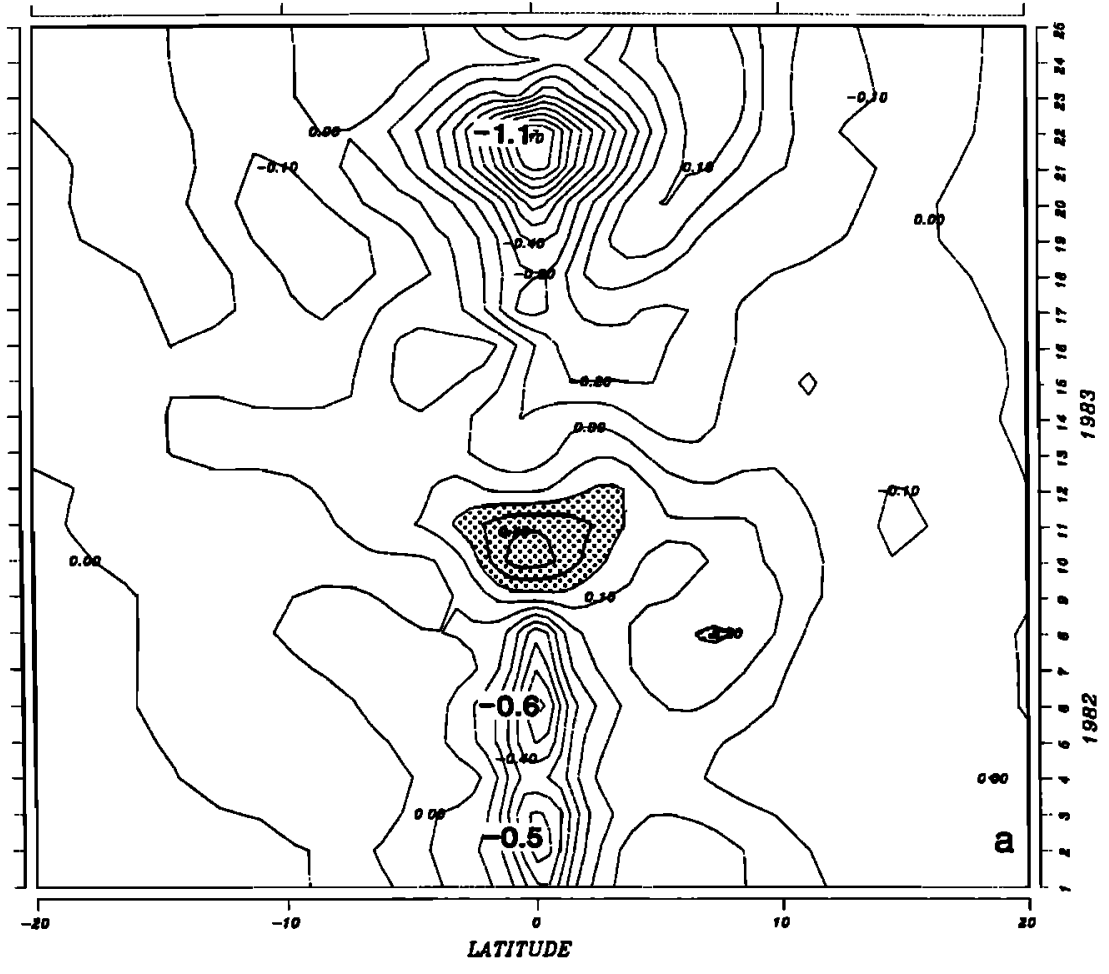

$\begin{array}{llllll}\text { REFERENCE LINE : } & 0.00 & \text { UNIT: } & S Q R T(m / s) & M I N=-1.12 & M E A N=-0.03 \\ \text { CONTOUR INTERVAL: } & 0.10 & & & M A X=0.46 & S T D V=0.16\end{array}$

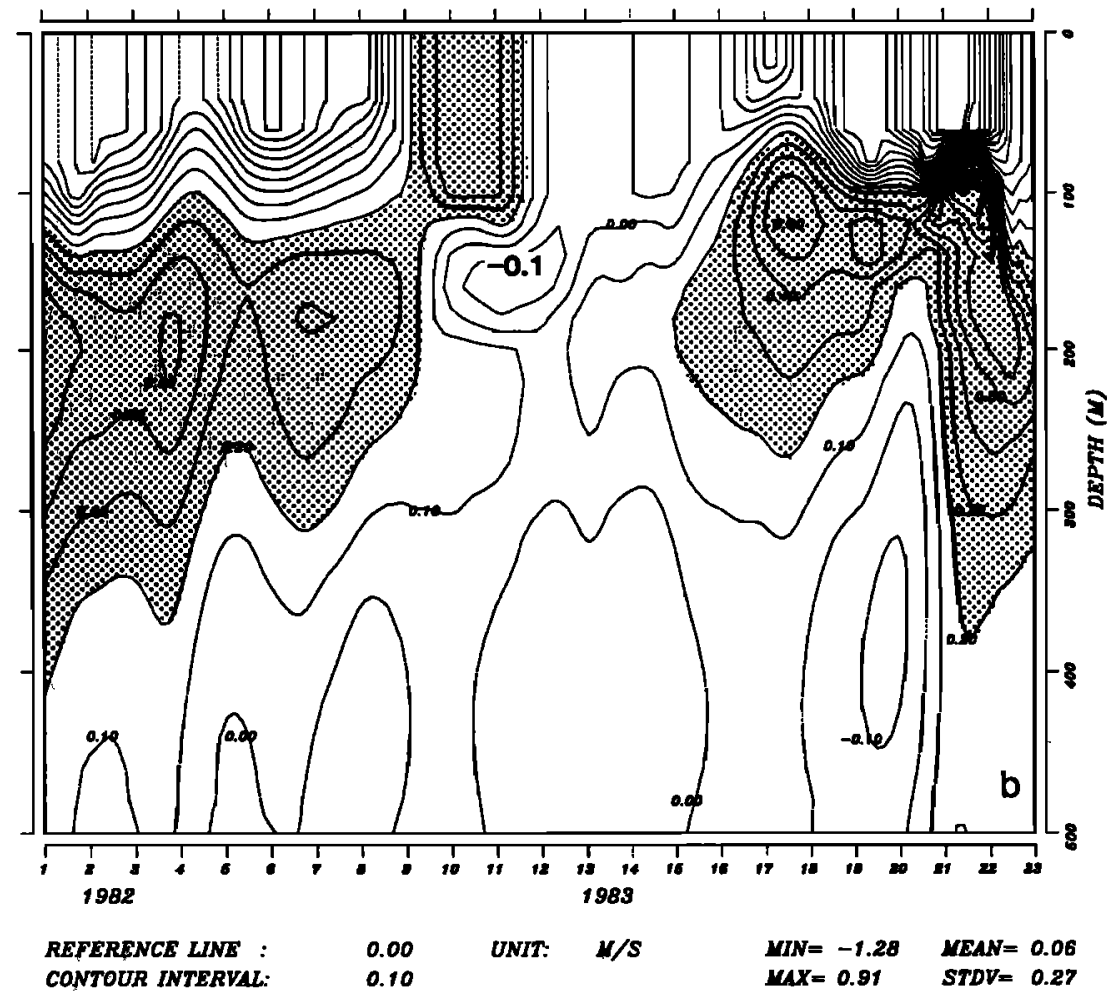

Fig. 12. Zonal surface current from case $\mathrm{D}$ as a function of $(a)$ latitude and time and $(b)$ depth and time during the $1982-1983$ time period. Stippled regions indicate current $\geq 20 \mathrm{~cm} \mathrm{~s}^{-1}$. 

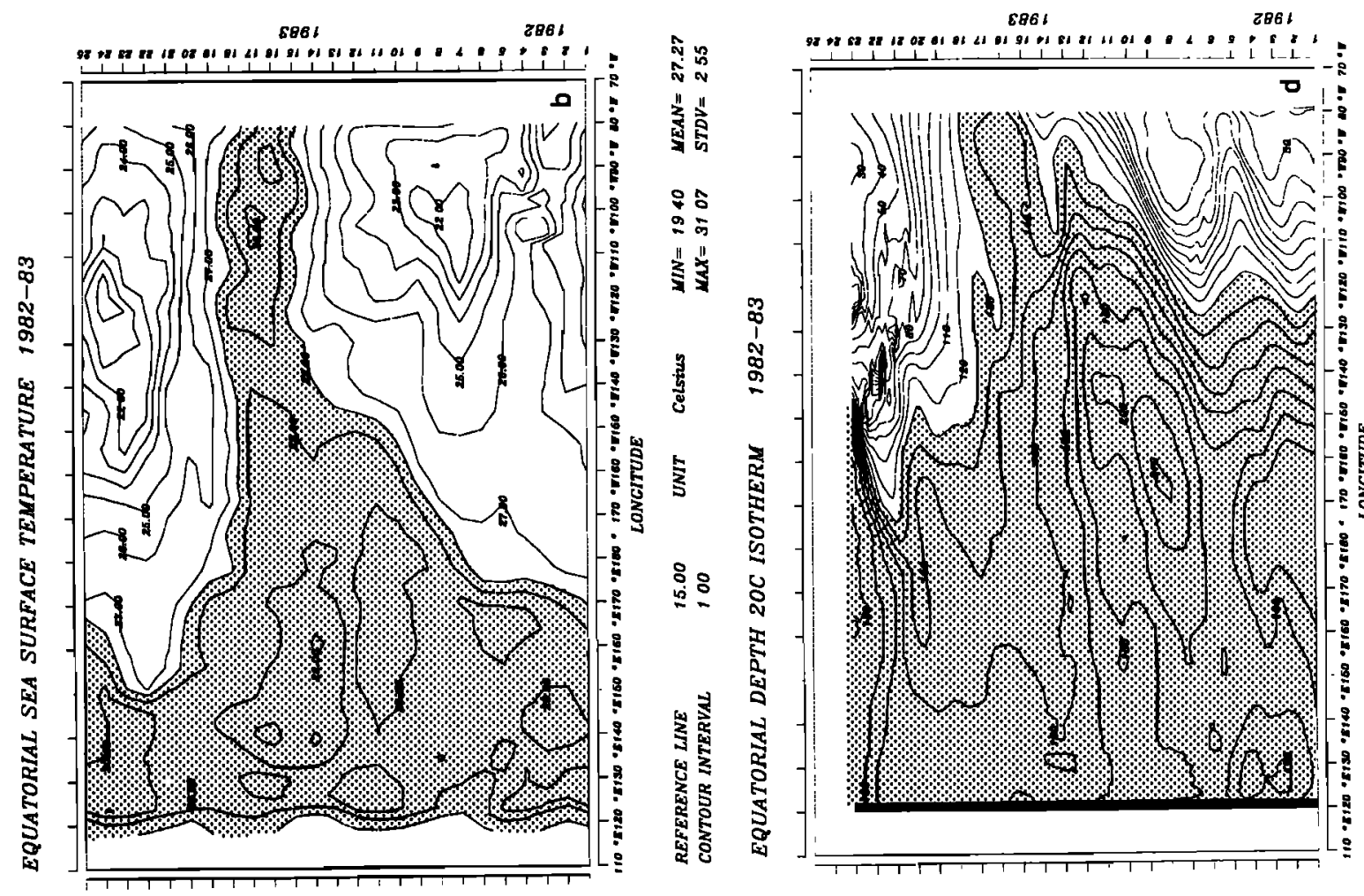

ฟ้ำ

○方兽营

ㄴ.

要

齐

紊

ํำ늘

.

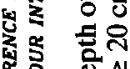

幽

छ)
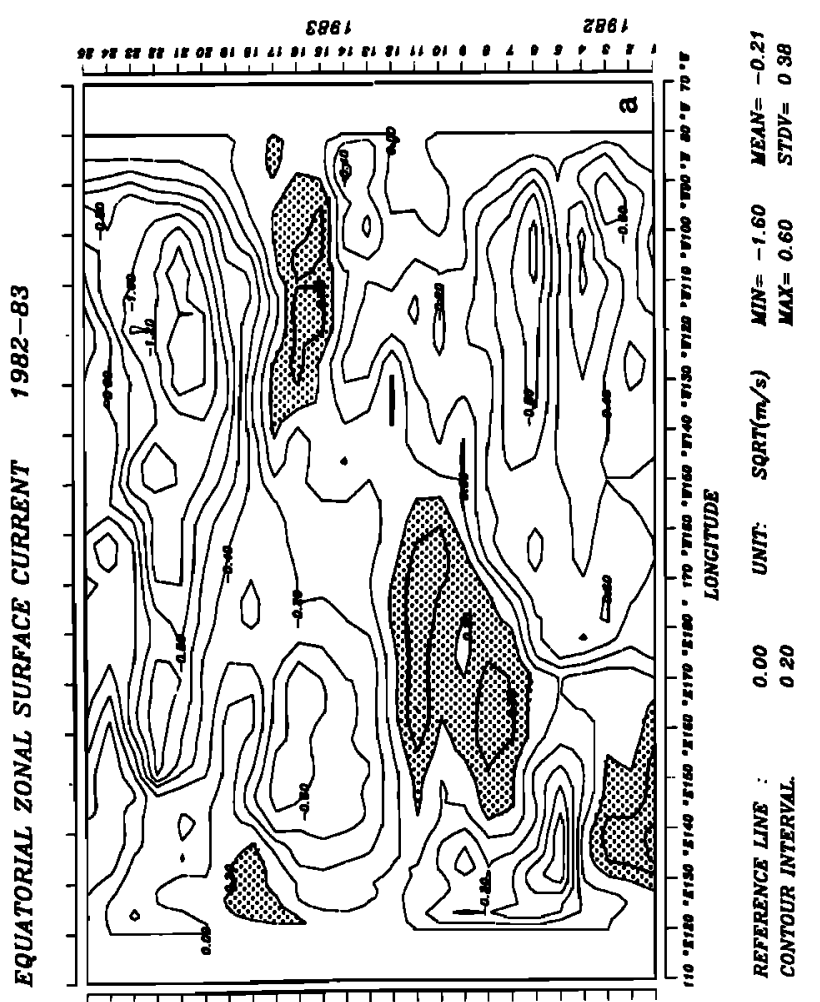

ค ฬ

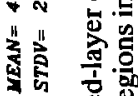

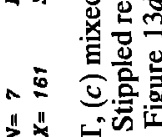

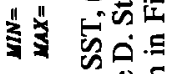

อ芯

起究

5 势吾

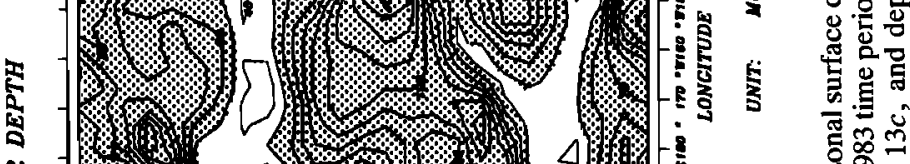

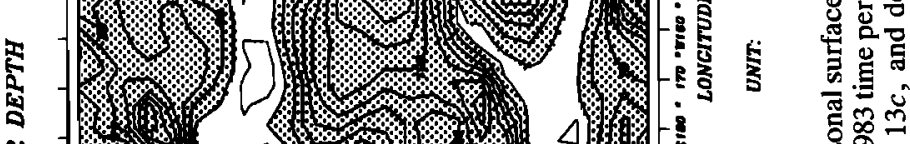

ำ สิ

药

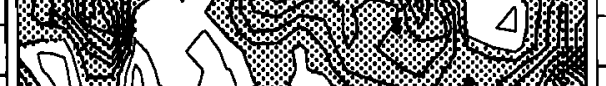

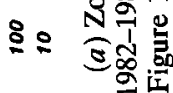

몬

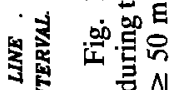

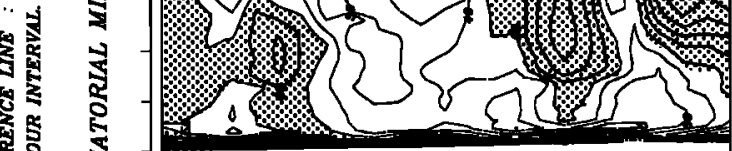

窟 

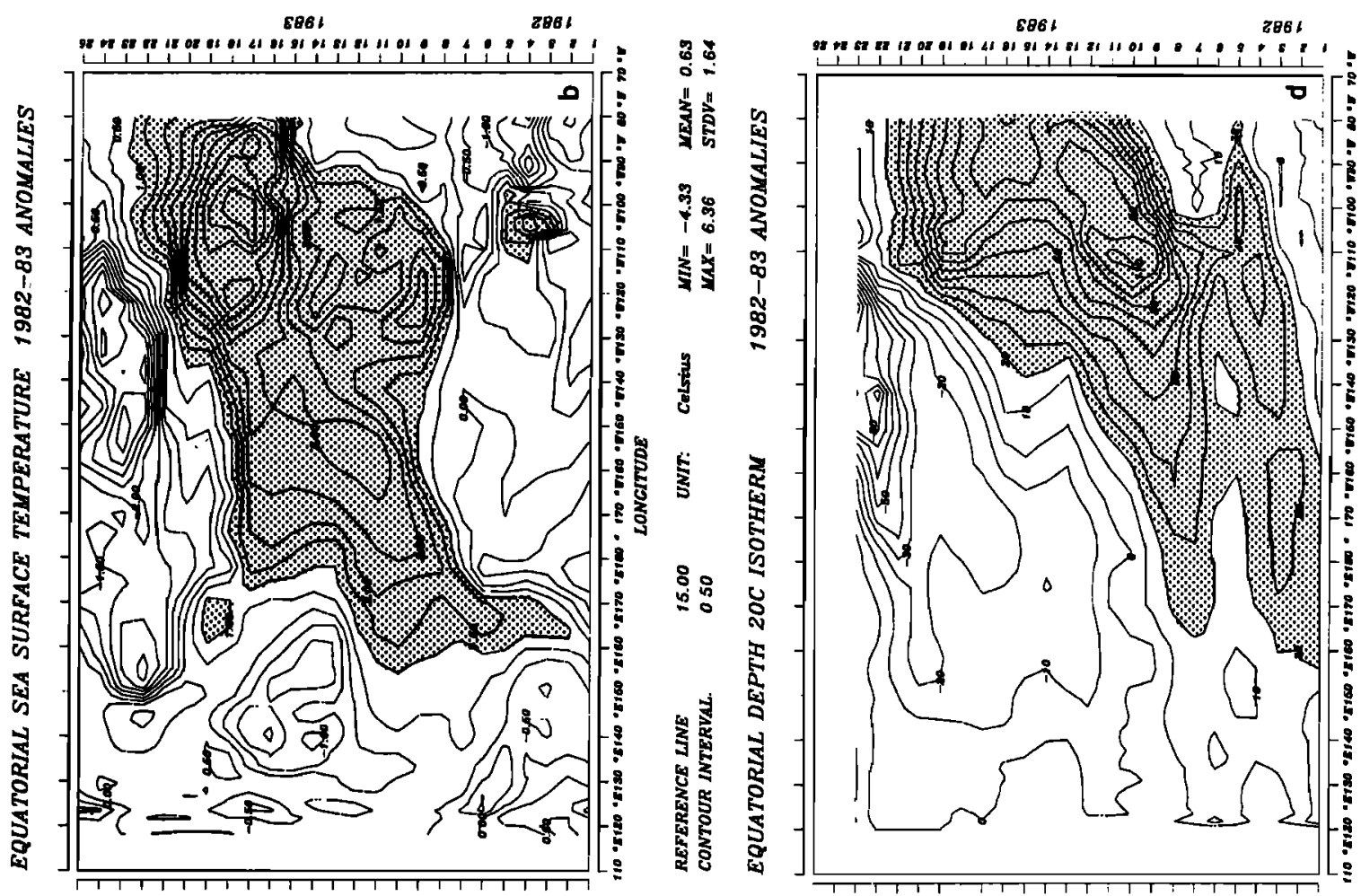

ㅇำ

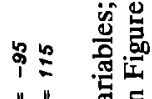

3ี

灵的す

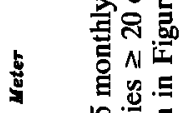

- $\quad$ 然

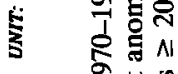

ㅇํㅇ을

》苞

ง 沓.

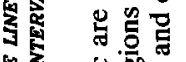

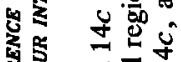

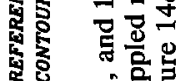

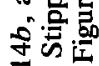

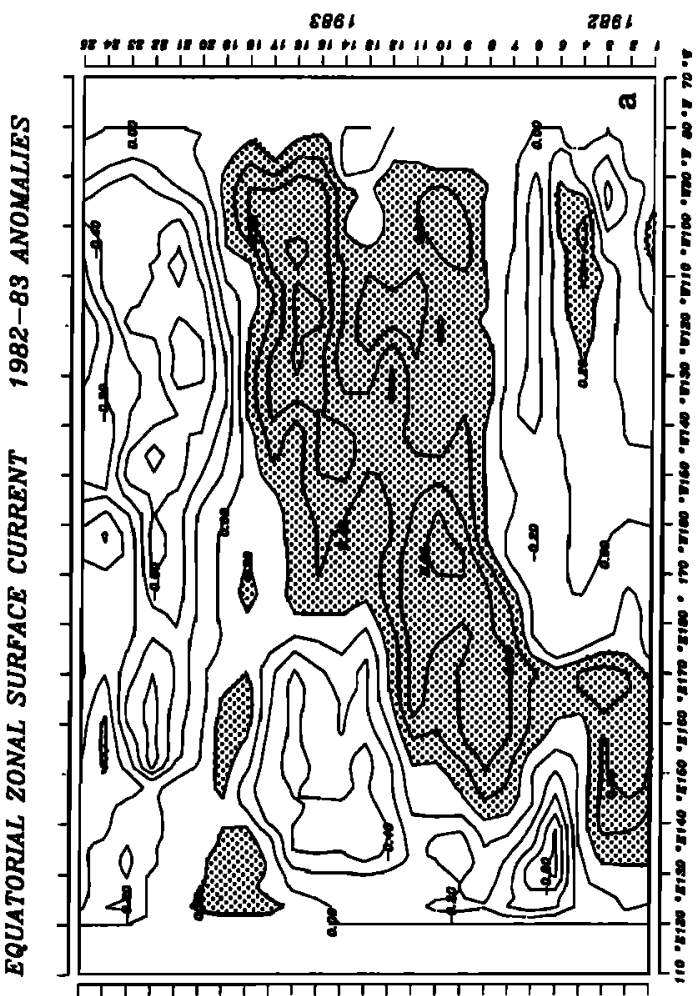

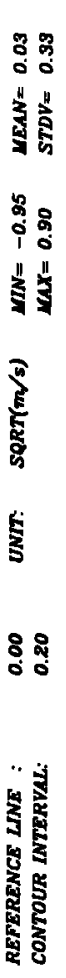

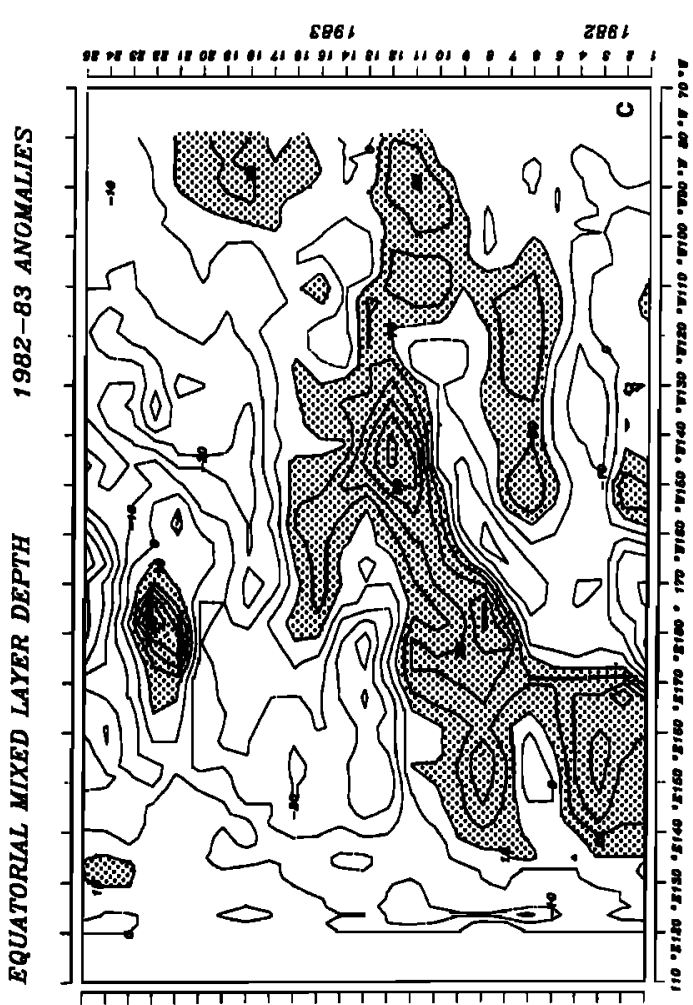

की.

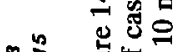

II

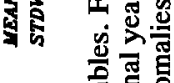

คั 覀县

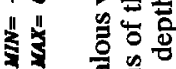

需最守

包 졸을

ษ

- ले

$5 \quad$ 达

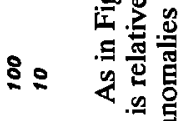

. 过荨氛

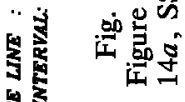



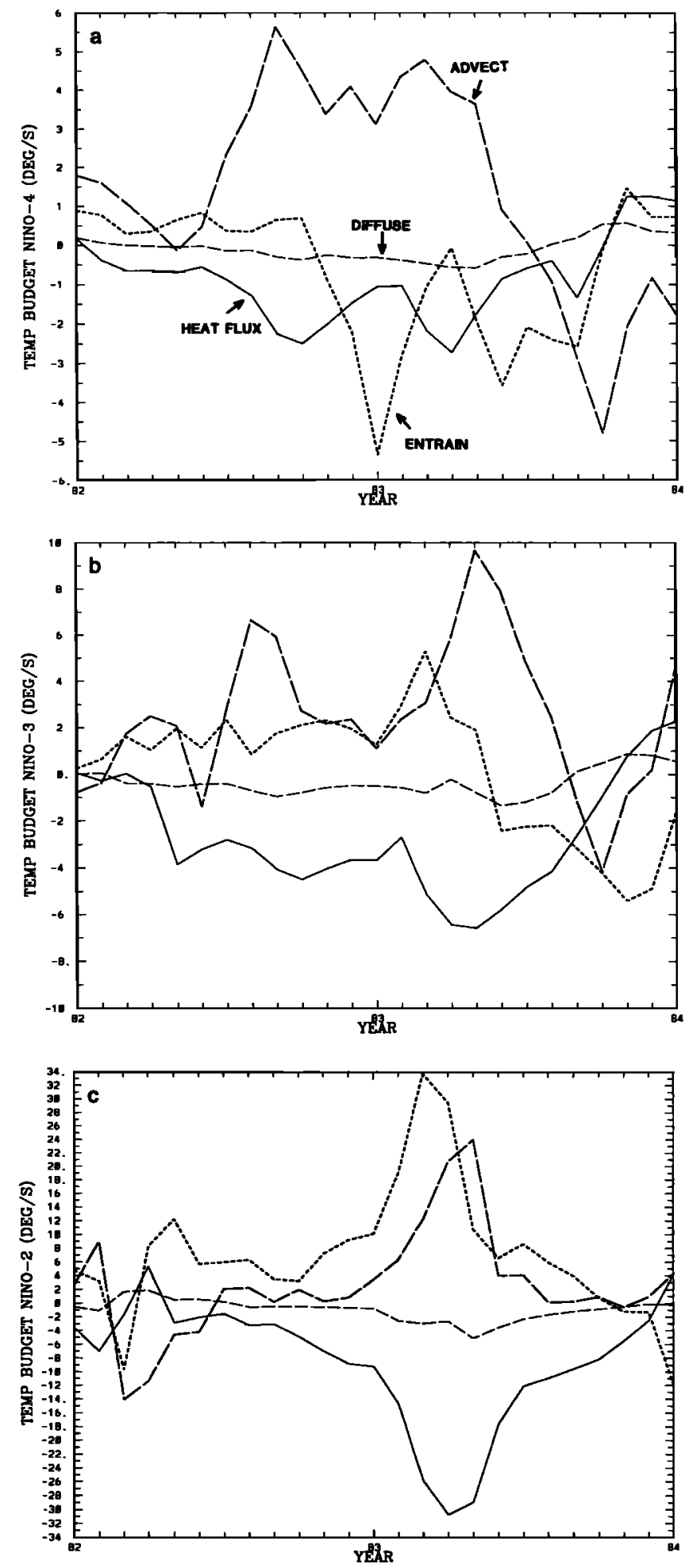

Fig. 15. Anomalous terms of the heat budget (equation (3)) for the surface bulk mixed layer model during 1982-1983, relative to the monthly-mean terms of case D, for the (a) Niño-4, (b) Niño-3, and (c) Niño-2 regions. Values are in units of $10^{-8} \mathrm{~K} \mathrm{~s}^{-1}$. Long-dashed lines indicate horizontal advection, medium dashes indicate horizontal diffusion, short-dashed lines indicate vertical mixing processes, and solid lines indicate surface heat flux.

$25 \%$ during the event, relative to the long-term climatological annual mean ( $\bar{Q}$ from the 1961-1973 run).

As a final depiction of the heat balance in the tropical Pacific, Figure 17 shows the long-term variation in the heat budget of the surface mixed layer of the warm pool region of the western Pacific, which is currently the subject of a major experimental effort called TOGA-COARE (Tropical OceanGlobal Atmosphere Coupled Ocean-Atmosphere Response Experiment). One primary focus of COARE concerns the magnitude of the long-term mean surface heat fluxes in the warm pool region (e.g., Lukas et al. [1991] and other papers in issue). The present model suggests a long-term mean surface heat flux into TOGA-COARE inner domain of about $40 \mathrm{~W} \mathrm{~m}^{-2}$, which is about twice the estimated upper bound in the region [Godfrey and Lindstrom, 1989; Gent, 1991; Barnett et al., 1991]. Part of the reason for this, as was mentioned previously, is that the equatorial cold tongue extends too far west because of unrealistically strong advection, resulting in a cold bias of SST and hence higher heat fluxes. Figure 17 suggests that the long-term budget is dominated by a balance between surface heat flux warming and cooling due to vertical mixing processes associated with upwelling. The figure also suggests that although the long-term mean effect of the horizontal advection of heat is small, there are many instances when horizontal advection is comparable in importance to the other two terms of the heat budget.

\section{Summary and Discussion}

We have examined the response of the tropical Pacific Ocean to observed surface winds using a sophisticated ocean general circulation model constructed in layer coordinates. The model climatology was first examined and found to be reasonably accurate in representing the major features of the climatological ocean fields. We then showed that it is also capable of reproducing some features of observed sea level, SST, and near-surface velocity anomalies. Some comparisons have been drawn with the performance of other models and revealed that although problems with the present model still exist, OPYC's response is similar in many respects to the response of the other models, suggesting that future improved versions of OPYC will be increasingly helpful in providing understanding of the processes of tropical ocean circulation and thermodynamics.

Novel elements of this study include the simulation of basin-scale tropical Pacific mixed-layer depth, the identification of a mean vertical velocity field which is fundamentally different from that of the GFDL model, an analysis of the heat budget in a variable-depth tropical Pacific surface mixed layer, and a discussion of some of the relationships among the anomalies of mixed-layer depth, thermocline depth, and SST.

A key feature in the OPYC model structure is that surface temperature and velocity are predicted from a bulk surface mixed-layer model rather than specified from the top grid point of a $z$ coordinate model or from a constant-depth SST model. The mixed-layer approach has both benefits and detractions. Among the benefits are that (1) surface fluxes penetrate immediately throughout the entire mixed layer rather than relying on the effects of grid point vertical diffusion parameterizations; (2) a well-defined volume for surface heat budget analyses is evident, making it unnecessary to rely on arbitrary choices of temperature/density jumps or constant depth grid boxes or surface layers; (3) we obtain a better representation of the thermal inertia of SST through the effects of space- and time-varying mixed-layer depth; and (4) we require fewer degrees of freedom in the 


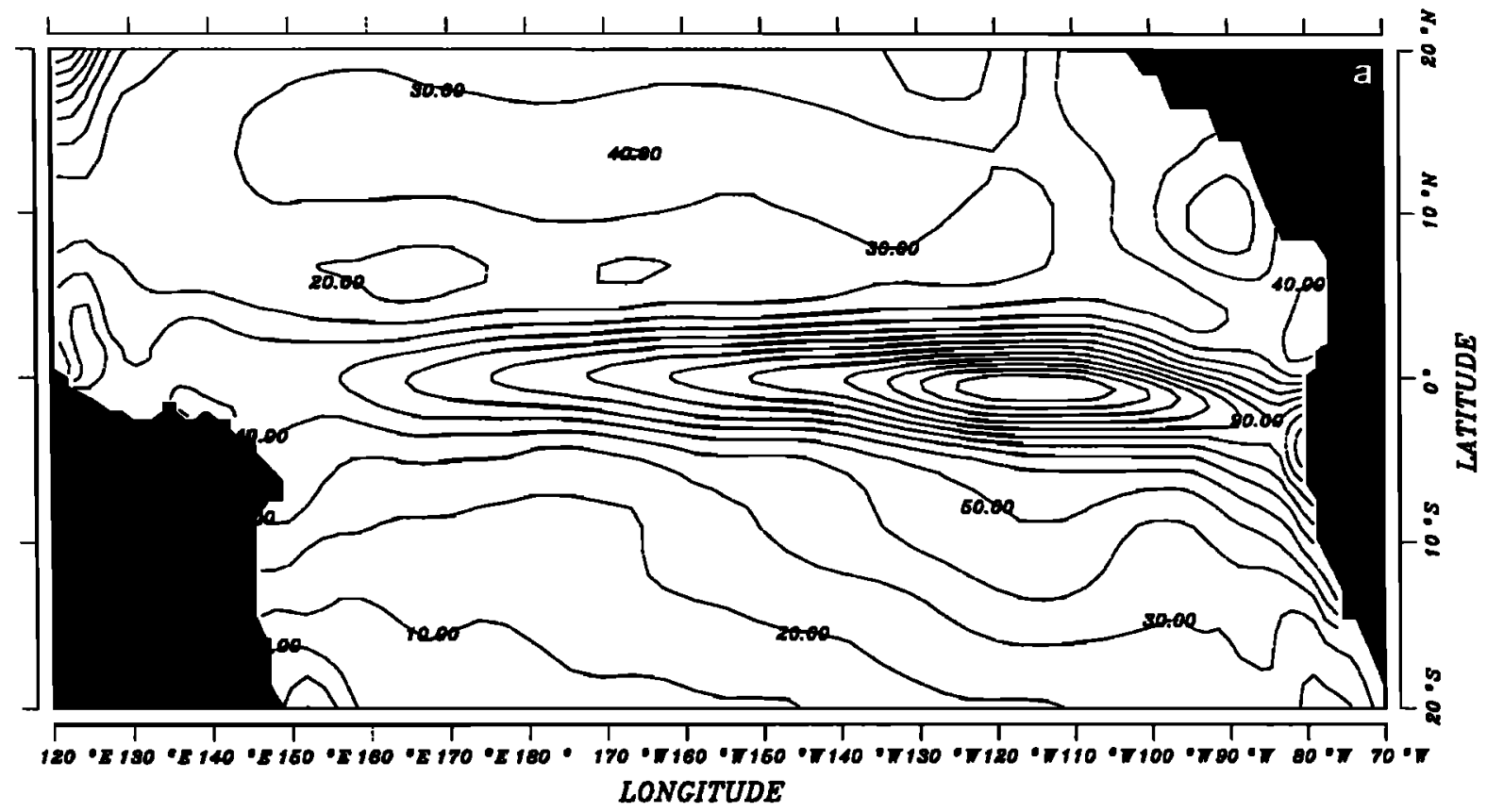
UNIT :
W/sqm
$M I N=-188.21 \quad M E A N=33.53$
CONTOUR INTERVAL:
10.00
$M A X=149.87 \quad S T D V=37.86$

\section{TOTAL SURFACE HEAT FLUX MAY82-MAY83}

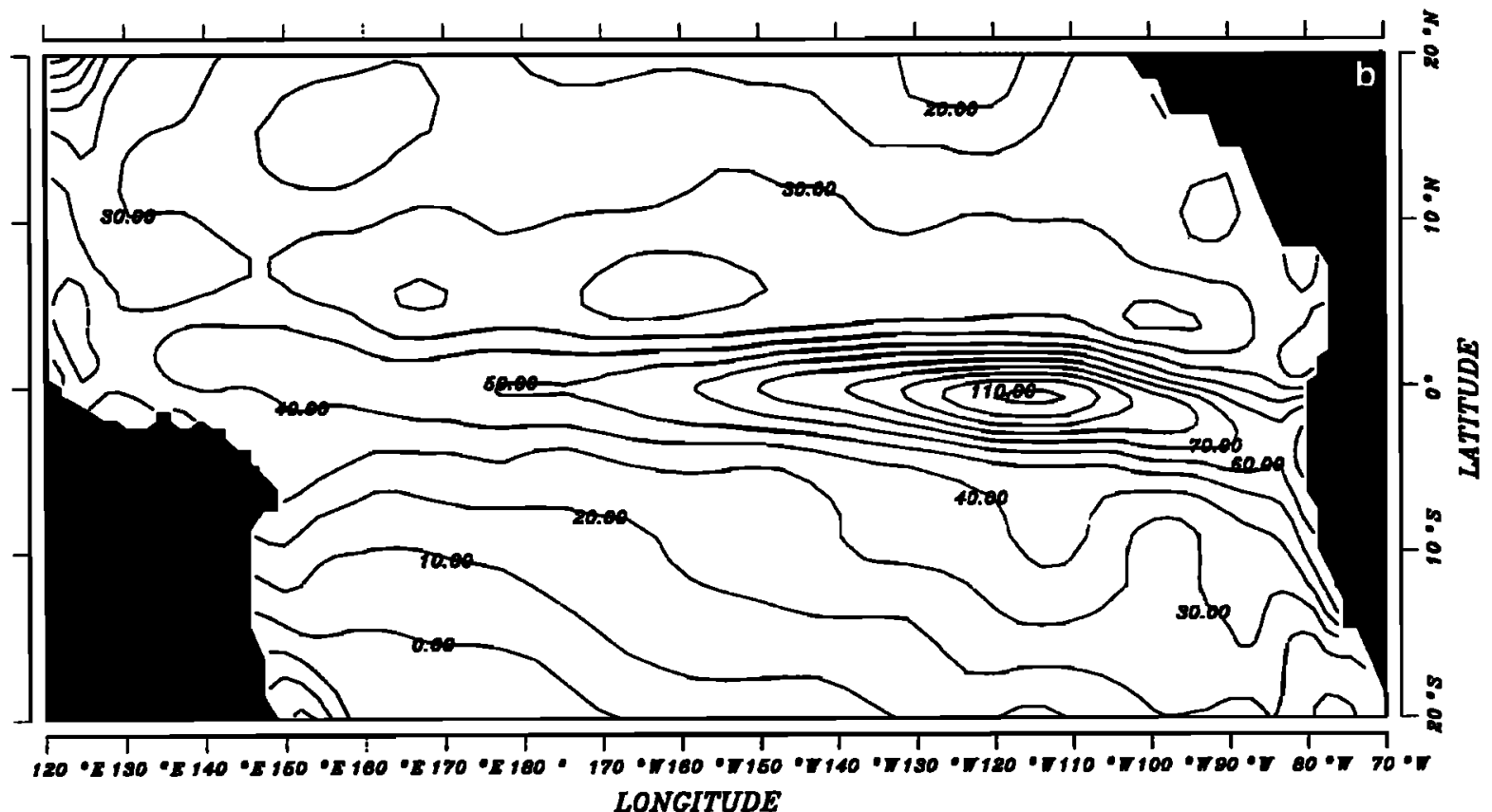

UNIT :

Fig. 16. (a) Annual mean surface heat flux ( $\bar{Q}$ in equation (13)) from case $\mathrm{C}$ and $(b)$ mean surface heat flux for the $\mathrm{El}$ Niño time period May 1982 to May 1983 from case D. 


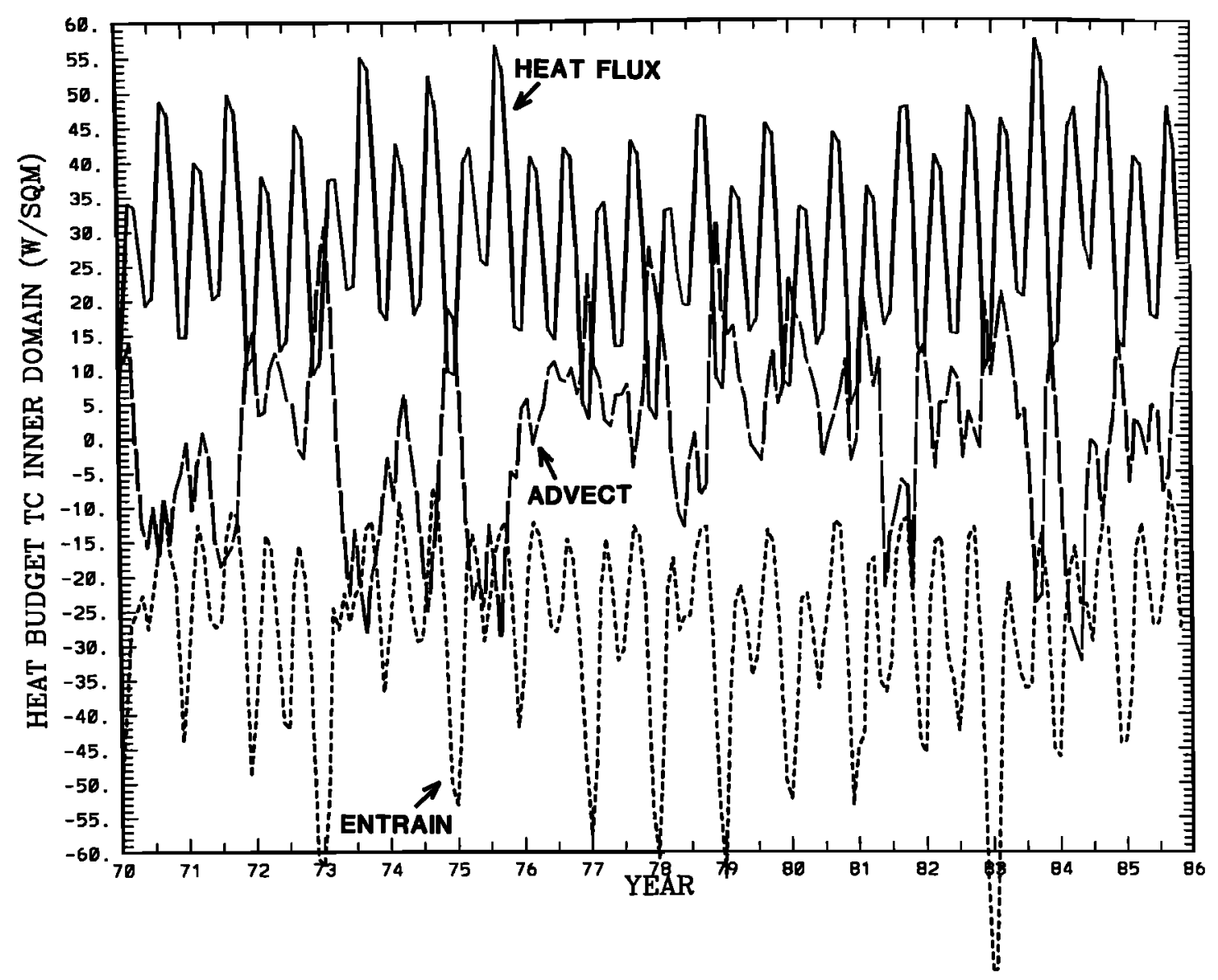

Fig. 17. Heat budget for the TOGA-COARE inner domain $\left(140^{\circ}-180^{\circ} \mathrm{E}, 10^{\circ} \mathrm{N}\right.$ to $\left.10^{\circ} \mathrm{S}\right)$ for the variable-depth surface mixed-layer model during the 1970-1985 run (case D). Value are in watts per square meter. The solid line is surface heat flux, the long-dashed line is horizontal advection, and the short-dashed line indicates vertical mixing (entrainment) processes.

vertical because we model the bulk response of the upper ocean. Among the problems with using a surface mixed layer model are that (1) velocity shears cannot be resolved in the mixed layer, (2) observations (e.g., ship drift velocity, SST) often correspond to the ocean surface rather than to the entire mixed layer, and (3) the structure of the turbulent surface mixed layer is poorly known for the tropical Pacific and thus the model cannot be easily verified. The problem of estimating month-to-month variability of TKE input into the upper ocean is common to both the $z$ coordinate and the OPYC model; in the $z$ coordinate model, enhanced vertical mixing must be invoked near the surface, while in the OPYC model we include estimates of the extra TKE needed for a realistically deep mixed layer.

Although we have shown that this layered general circulation model can perform relatively well, in some ways $z$ coordinate models appear to be superior to the present model. Therefore we are presently attempting to improve this model by carrying out additional experiments with a new version of this model which invokes, among other new features, a potential vorticity and energy conserving horizontal discretization scheme (based on the Bleck and Boudra [1981] formulation). The main results we hope to achieve with the new version of OPYC are to increase the speed of the Equatorial Undercurrent and decrease the length of the cold tongue (features which we have indeed found in prelim- inary runs with the new discretization scheme), to suppress the rather strong upwelling which occurs along the equator (through an improved cross-isopycnal mixing parameterization, perhaps akin to that of Pacanowski and Philander [1981]), to increase the sharpness of the thermocline (by including the formation of Antarctic bottom water to help close the meridional circulation cell in the model southern ocean) and to incorporate a more practical heat flux anomaly formulation than (13) (thereby allowing atmospheric feedback effects, either by coupling a statistically or physically based atmosphere to OPYC or by implementing approximations to the heat flux parameterizations akin to those of Seager et al. [1988] or the GFDL modeling strategy [PS85; Wells and King-Hele, 1990, Harrison, 1991]). Through analyses of models such as the present one, we can better ascertain the relative importance of the latent heat fluxes, radiative heat fluxes, and the various internal ocean flux processes of different regions of the tropical Pacific during the evolution of El Niños.

Acknowledgments. Support was provided by NOAA grant NA90-AA-D-CP526, NASA grant NAG5-236, the Vettleson Foundation, and the University of California INCOR program for global climate change. Supercomputing resources were provided by the Department of Energy through Lawrence Livermore National Laboratory and by the National Science Foundation through the San Diego Supercomputer Center. Jack Ritchie (SIO) helped with run- 
ning the model and processing much of the model data. The FSU wind data and the FSU model results were generously supplied by D. Legler and J. O'Brien, and the sea level data were provided by $\mathrm{K}$. Wyrtki. The comments of the two reviewers were very helpful in clarifying the presentation of our results.

\section{REFERENCES}

Barnett, T. P., M. Latif, E. Kirk, and E. Roeckner, On ENSO physics, J. Clim., 4, 487-515, 1991.

Bleck, R., and D. B. Boudra, Initial testing of a numerical ocean circulation model using a hybrid (quasi-isopycnic) vertical coordinate, J. Phys. Oceanogr., 11, 755-770, 1981.

Busalacchi, A. J., K. Takeuchi, and J. J. O'Brien, Interannual variability of the tropical Pacific-Revisited, J. Geophys. Res., $88,7551-7562,1983$.

Chao, Y., D. Halpern, and C. R. Mechoso, A Pacific Ocean general circulation model for satellite data assimilation, JPL Publ. 91-9, 32 pp., Jet Propul. Lab., Pasadena, Calif., 1991.

Firing, E., R. Lukas, J. Sadler, and K. Wyrtki, Equatorial Undercurrent disappears during 1982-1983 El Niño, Science, 222, 1121-1123, 1983.

Gent, P. R., The heat budget of the TOGA-COARE domain in an ocean model, J. Geophys. Res., 96, 3323-3330, 1991.

Godfrey, J. S., and E. J. Lindstrom, The heat budget of the western equatorial Pacific, J. Geophys. Res., 94, 8007-8017, 1989.

Goldenberg, S. B., and J. J. O'Brien, Time and space variability of tropical Pacific wind stress, Mon. Weather Rev., 109, 1190-1207, 1981.

Gordon, C., and R. A. Corry, A model simulation of the seasonal cycle in the tropical Pacific Ocean using climatological and modeled surface forcing, J. Geophys. Res., 96, 847-864, 1991.

Graham, N. E., T. P. Barnett, V. G. Panchang, O. M. Smedstad, J. J. O'Brien, and R. M. Chervin, The response of a linear model of the tropical Pacific to surface winds from the NCAR general circulation model, J. Phys. Oceanogr., 19, 1222-1243, 1989.

Halpern, D., Observations of annual and El Niño thermal and flow variations at $0^{\circ}, 110^{\circ} \mathrm{W}$ and $0^{\circ}, 95^{\circ} \mathrm{W}$ during $1980-1985, J$. Geophys. Res., 92, 8197-8212, 1987.

Halpern, D., R. A. Knox, D. S. Luther, and S. G. H. Philander, Estimates of equatorial upwelling between $140^{\circ}$ and $110^{\circ} \mathrm{W}$ during 1984, J. Geophys. Res., 94, 8018-8020, 1989.

Harrison, D. E., Equatorial sea surface temperature sensitivity to net surface heat flux: Some ocean circulation model results, $J$. Clim., 4, 539-549, 1991.

Harrison, D. E., The tropical Pacific seasonal cycle of SST: An ocean circulation model simulation and its thermal balance, $J$. Clim., in press, 1992.

Harrison, D. E., W. S. Kessler, and B. S. Giese, Ocean circulation model hindcasts of the 1982-1983 El Niño: Thermal variability along the ship-of-opportunity tracks, J. Phys. Oceanogr., 19, 397-418, 1989.

Harrison, D. E., B. S. Giese, and E. S. Sarachik, Mechanisms of SST change in the equatorial waveguide during the 1982-1983 ENSO, J. Clim., 3, 173-188, 1990.

Hellerman, S., and M. Rosenstein, Normal monthly wind stress over the world ocean with error estimates, J. Phys. Oceanogr., $13,1093-1104,1983$.

Jia, Y. L., N. C. Wells, and M. A. Rowe, A simulation of the 1982-1983 El Niño, J. Geophys. Res., 95, 5395-5403, 1990.

Kraus, E. B., and J. S. Turner, A one-dimensional model of the seasonal thermocline, Tellus, 1, 88-97, 1967.

Latif, M., Tropical ocean circulation experiments, J. Phys. Oceanogr., 17, 246-263, 1987.

Levitus, S., Climatological atlas of the world ocean, NOAA Prof. Pap. 13, 173 pp., U.S. Govt. Print. Off., Washington, D. C., 1982.

Lukas, R., P. Webster, and J. Picaut, Papers from the western Pacific International Meeting and Workshop on TOGA/COARE, J. Geophys. Res., 96, 3123-3124, 1991.

Luther, D. S., and E. S. Johnson, Eddy energetics in the upper equatorial Pacific during the Hawaii-to-Tahiti shuttle experiment, J. Phys. Oceanogr., 20, 913-944, 1990.

McCreary, J. P., Eastern tropical ocean response to changing wind systems: With application to El Niño, J. Phys. Oceanogr., 6, 632-645, 1976.

McPhaden, M. J., and S. P. Hayes, Moored velocity, temperature and wind measurements in the equatorial Pacific Ocean: A review of scientific results, 1985-90, in International TOGA Scientific Conference Proceedings, WCRP-43, WMO/TD 379, pp. 59-69, World Meteorol. Organ., Geneva, 1990.

McPhaden, M. J., and J. Picaut, El Niño-Southern Oscillation displacements of the western equatorial Pacific warm pool, Science, 250, 1385-1388, 1990.

McPhaden, M. J., D. V. Hansen, and P. L. Richardson, A comparison of ship drift, drifting buoy, and current meter mooring velocities in the Pacific South Equatorial Current, J. Geophys. Res., 96, 775-782, 1991.

Oberhuber, J. M., About some numerical methods used in an ocean general circulation model with isopycnic coordinates, in $A d-$ vanced Physical Oceanographic Numerical Modeling, edited by J. J. O'Brien, pp. 511-522, D. Reidel, Norwell, Mass., 1986.

Oberhuber, J. M., An atlas based on the 'COADS' data set: The budgets of heat, buoyancy and turbulent kinetic energy at the surface of the global ocean, Rep. 15, 199 pp., Max-Planck-Inst. für Meteorol., Hamburg, Germany, 1988.

Oberhuber, J. M., Simulation of the Atlantic circulation with a coupled sea ice-mixed layer-isopycnal general circulation model, Rep. 59, 86 pp., Max-Planck-Inst. für Meteorol., Hamburg, Germany, 1990.

Pacanowski, R. C., and S. G. H. Philander, Parameterization of vertical mixing in numerical models of tropical oceans, J. Phys. Oceanogr., II, 1443-1451, 1981.

Philander, S. G. H., El Niño, La Niña, and the Southern Oscillation, 293 pp., Academic, San Diego, Calif., 1990.

Philander, S. G. H., and A. D. Siegel, Simulation of El Niño of 1982-1983, in Coupled Ocean-Atmosphere Models, edited by J. C. J. Nihoul, pp. 517-541, Elsevier, New York, 1985.

Philander, S. G. H., W. J. Hurlin, and A. D. Siegel, Simulation of the seasonal cycle of the tropical Pacific Ocean, J. Phys. Oceanogr., 17, 1986-2002, 1987.

Richardson, P. L., and T. K. McKee, Surface velocity in the equatorial oceans (20N-20S) calculated from historical ship drifts, Tech. Rep. WHOI-89-9, Woods Hole Oceanogr. Inst., Woods Hole, Mass., 1989.

Schopf, P. S., On equatorial waves and El Niño, I, Effects of air-sea thermal coupling, J. Phys. Oceanogr., 13, 936-948, 1983.

Schopf, P. S., and M. A. Cane, On equatorial dynamics, mixed layer physics and sea surface temperature, J. Phys. Oceanogr., 13, 917-935, 1983.

Seager, R., Modeling tropical Pacific sea surface temperature: 1970-87, J. Phys. Oceanogr., 19, 419-434, 1989.

Seager, R., S. E. Zebiak, and M. A. Cane, A model of the tropical Pacific sea surface temperature climatology, J. Geophys. Res., 93, 1265-1280, 1988.

Smagorinsky, J. S., General circulation experiments with the primitive equations, I, The basic experiment, Mon. Weather Rev., 91, 99-164, 1963.

UNESCO, (United Nations Educational, Scientific, and Cultural Organization), The practical salinity scale 1978 and the international equation of state of seawater 1980, Tech. Pap. Mar. Sci., 36 pp., 13-21, Paris, 1981.

Wells, N. C., and S. King-Hele, Parameterization of tropical ocean heat flux, Q. J. R. Meteorol. Soc., 116, 1213-1224, 1990.

Woodruff, S. D., R. J. Slutz, R. L. Jenne, and P. M. Steurer, A comprehensive ocean-atmosphere data set, Bull. Am. Meteorol. Soc., 68, 1239-1250, 1987.

Wright, P., An atlas based on the 'COADS' data set: Fields of mean wind, cloudiness and humidity at the surface of the global ocean, Rep. 14, 70 pp., Max-Planck-Inst. für Meteorol., Hamburg, Germany, 1988 .

Wyrtki, K., and B. Kilonsky, Mean water and current structure during the Hawaii-to-Tahiti Shuttle experiment, J. Phys. Oceanogr., 14, 242-254, 1984.

T. P. Barnett, N. E. Graham, and A. J. Miller, Scripps Institution of Oceanography, Mail Code 0224, University of California, San Diego, La Jolla, CA 92093.

J. M. Oberhuber, Meteorologisches Institut, Universität Hamburg, Bundesstrasse 55, 2000 Hamburg 13, Germany.

(Received June 28, 1991; revised January 21, 1992; accepted January 22, 1992.) 